BMC

Genomics

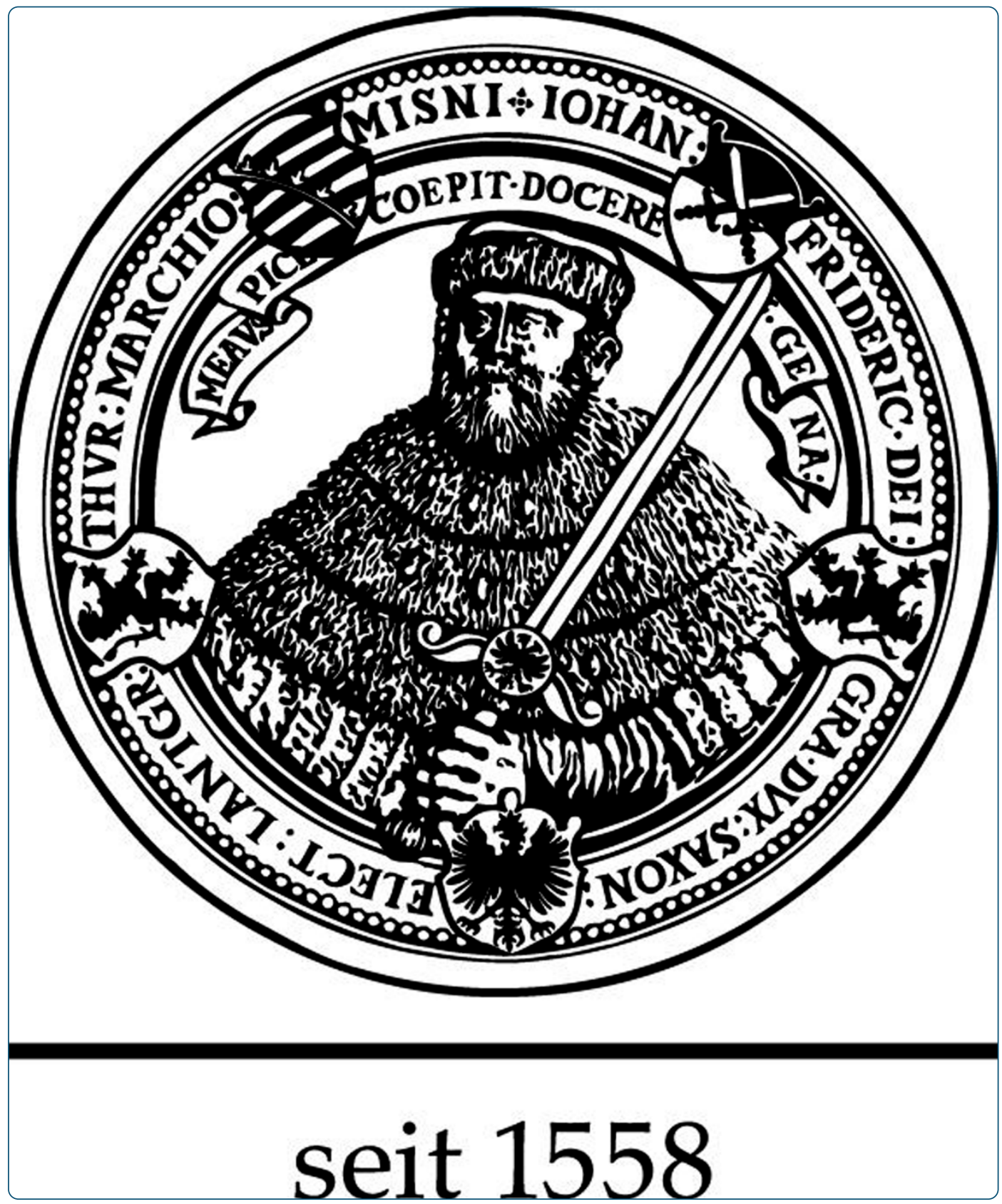

Genomewide comparison and novel ncRNAs of Aquificales

Lechner et al.

C Biomed Central

Lechner et al. BMC Genomics 2014, 15:522

http://www.biomedcentral.com/1471-2164/15/522 


\title{
Genomewide comparison and novel ncRNAs of Aquificales
}

\author{
Marcus Lechner ${ }^{1 \dagger}$, Astrid I Nickel ${ }^{1 \dagger}$, Stefanie Wehner ${ }^{2 \dagger}$, Konstantin Riege $^{2}$, Nicolas Wieseke ${ }^{3}$, \\ Benedikt M Beckmann ${ }^{4}$, Roland K Hartmann ${ }^{1 *}$ and Manja Marz ${ }^{2^{*}}$
}

\begin{abstract}
Background: The Aquificales are a diverse group of thermophilic bacteria that thrive in terrestrial and marine hydrothermal environments. They can be divided into the families Aquificaceae, Desulfurobacteriaceae and Hydrogenothermaceae. Although eleven fully sequenced and assembled genomes are available, only little is known about this taxonomic order in terms of RNA metabolism.

Results: In this work, we compare the available genomes, extend their protein annotation, identify regulatory sequences, annotate non-coding RNAs (ncRNAs) of known function, predict novel ncRNA candidates, show idiosyncrasies of the genetic decoding machinery, present two different types of transfer-messenger RNAs and variations of the CRISPR systems. Furthermore, we performed a phylogenetic analysis of the Aquificales based on entire genome sequences, and extended this by a classification among all bacteria using $16 \mathrm{~S}$ rRNA sequences and a set of orthologous proteins.

Combining several in silico features (e.g. conserved and stable secondary structures, GC-content, comparison based on multiple genome alignments) with an in vivo dRNA-seq transcriptome analysis of Aquifex aeolicus, we predict roughly 100 novel ncRNA candidates in this bacterium.

Conclusions: We have here re-analyzed the Aquificales, a group of bacteria thriving in extreme environments, sharing the feature of a small, compact genome with a reduced number of protein and ncRNA genes. We present several classical ncRNAs and riboswitch candidates. By combining in silico analysis with dRNA-seq data of A. aeolicus we predict nearly 100 novel ncRNA candidates.
\end{abstract}

Keywords: Aquificales, Thermophiles, ncRNA, Aquificaceae, Desulfurobacteriaceae, Hydrogenothermaceae

\section{Background}

Aquificales are gram-negative, non-sporulating bacteria that are thermophilic to hyperthermophilic [1,2], living in terrestrial and marine hot springs. They are autotrophs that primarily fix carbon by the tricarboxylic acid (TCA) cycle [3-5]. The hyperthermophile A. aeolicus, living under extreme temperatures of up to $95^{\circ} \mathrm{C}$, has been proposed to have adopted $10 \%$ of its protein-coding genes by horizontal gene transfer [6,7] from Archaea. Accumulation of all the special properties of thermophiles (also

*Correspondence: roland.hartmann@staff.uni-marburg.de; manja@uni-jena.de † Equal contributors

${ }^{1}$ Institut für Pharmazeutische Chemie, Philipps-Universität Marburg,

Marbacher Weg 6, 35032 Marburg, Germany

${ }^{2}$ Faculty of Mathematics and Computer Science, Friedrich-Schiller-University

Jena, Leutragraben 1, 07743 Jena, Germany

Full list of author information is available at the end of the article referred to as accumulation profiles [8]) are rarely understood. Special protein-protective mechanisms have been analyzed $[9,10]$, but we are far away from a comprehensive understanding of the molecular biology of extremophilic bacteria. Beyond idiosyncratic features of Aquificales genomes, our interest focussed on their transcriptomes. Experimentally, we performed a deep sequencing analysis on the model hyperthermophile $A$. aeolicus with the primary goal of identifying novel ncRNAs candidates. NcRNAs are known to have various functions in all domains of life. Apart from their general importance as gene expression regulators [11-13], ncRNAs are involved in processing [14] and translation [15] of other genes, in defending genomes from viral invasion [16], in shaping and maintenance of bacterial chromosome architecture [17], and they can even be multifunctional $[18,19]$. According to 
16S rRNA analysis, the Aquificales constitute the most deeply rooted bacterial group [20]. However, proteinbased phylogenetic reconstructions are not in line with this model [21-26].

We compared the genomes of the three Aquificales families, i.e. Aquificaceae, Hydrogenothermaceae and Desulfurobacteriaceae. We have extended the protein annotation of the mentioned Aquificales and reconstructed the phylogenetic position of these species based on $16 \mathrm{~S}$ rRNAs as well as on a set of orthologous proteins. Moreover, we have identified ncRNAs based on known homologs and present a complete set of novel ncRNA candidates based on sequence analyses and deep sequencing data obtained for $A$. aeolicus. For selected ncRNA loci, we provide independent experimental evidence for their expression.

\section{Methods}

\section{Genomes}

We analyzed the genomes of the following species split into their respective families:

- Aquificaceae: Aquifex aeolicus VF5 (AAE), Hydrogenivirga sp. 128-5-R1-1 (HVI), Hydrogenobacter thermophilus TK-6 (HTH), Thermocrinis ruber (TRU), Thermocrinis albus DSM 14484 (TAL), Hydrogenobaculum sp. Y04AAS1 (HBA),

- Hydrogenothermaceae: Sulfurihydrogenibium sp. YO3AOP1 (SSP), Sulfurihydrogenibium azorense Az-Fu1 (SAZ), Persephonella marina EX-H1 (PMA), and

- Desulfurobacteriaceae: Desulfobacterium thermolithotrophum DSM 11699 (DTH), and Thermovibrio ammonificans HB-1 (TAM).

Accession numbers and sources of genomes are listed in the electronic Supplemental Material http://www.rna. uni-jena.de/supplements/aquificales/index.html. Wholegenome alignments were constructed using Pomago (v.1.0) [27] and TBA (v.11.2) (threaded blockset aligner) [28] with default parameters. Pomago alignments were computed separately for each species as reference. The TBA alignment was projected to each of the reference genomes. Coverage, alignment quality (Weighted sumof-pairs score - WSoP [29]) and gap ratio are given in Figure 1.

\section{Extension of protein annotation}

We used BacProt (publication in progress, see [33] for details) to complement the present annotation of protein-coding genes for each Aquificales genome. It uses a database of groups of orthologous protein-coding genes present in most bacteria [34]. Matches in the genome of interest are annotated, and species-specific features like codon usage, Shine-Dalgarno sequences, Pribnow box motifs and Rho-independent terminators are used to predict additional protein-coding genes. To actually achieve a de novo annotation, we excluded all Aquificales genes from the reference database. Alternative start codons like ATT and CTG were considered as well [35-37]. Re-annotated and previously annotated proteins (genomic positions and sequences) and statistics (mono-/di-nucleotide distribution, position and occurrence of Shine-Dalgarno sequence motifs and Pribnow boxes) for each species are provided in the Supplemental Material.

\section{Annotation of ncRNAs by homology}

We used GORAP (v.1.0, publication in progress) to annotate ncRNAs in the following manner: transferRNAs (tRNAs) were detected by tRNAscan-SE (v.1.3.1) [38] with the option $-B$ for bacteria. Split tRNAs were searched using SPLITS (v.1.1) [39]. By applying ARAGORN (v.1.2), we searched for tRNAs containing introns [40]. Searches for RNase P RNA were conducted with Bcheck (v.1.0) [41]. For the detection of putative CRISPR loci, crt (v1.2) [42] and CRISPRFinder [43] were used. We searched for cas protein genes by blast (v.2.2.26, E-value $\leq 10^{-4}$ ) [44] based on known cas genes (downloaded from Uni Prot (downloaded Jan. 2013) [45]).

To find further ncRNAs, we used blast and Infernal (v.1.1rc2) [46]. Seed sequences from the Rfam (v.11.0) database [47] and European Ribosomal RNA Database [48] were used as query with an Evalue $\leq 0.001$ for blast and the Rfam-provided family specific noise cutoff for Infernal.

NcRNAs expected to escape from detection (e.g. $6 \mathrm{~S}$ RNA) were searched in a second step with rnabob [49] for short motif search in combination with RNAsubopt, RNAduplex, RNAcofold, RNAalifold and RNAup from the RNA Vienna Package (v.2.0) [50-53]. For verification, we aligned candidates with Clustalw (v.2.0.10) [54] or Locarnate (v.1.7.7.1) [55]. Stockholm alignments were adjusted by hand in the Emacs Ralee mode [56].

Resulting Stockholm alignments are supplied in the Supplemental Material in the General Feature Format (gff) as well as in Fasta (fa) and Stockholm (stk) formats.

\section{Phylogenetic reconstruction}

Protein-based phylogeny was performed based on the official NCBI [57] annotations for 42 bacteria shown in the Supplemental Material. In addition to eleven Aquificales species, we included two Archaea as outgroup and a wide phylogenetic range of 29 bacterial species representing all bacterial clades. 


\begin{tabular}{|c|c|c|c|c|c|c|c|c|c|c|c|}
\hline \multirow[b]{2}{*}{ Species } & \multicolumn{2}{|c|}{$\longmapsto$} & \multicolumn{3}{|c|}{$\overline{l \Gamma}$} & & & \\
\hline & AAE & $\mathrm{HVI}{ }^{*}$ & HTH & TAL & TRU & HBA & PMA & SAZ & SSP & DTH & TAM \\
\hline \multicolumn{12}{|c|}{ General Features } \\
\hline Optimal temperature & $85^{\circ} \mathrm{C}$ & $72^{\circ} \mathrm{C}$ & $70-75^{\circ} \mathrm{C}$ & $80^{\circ} \mathrm{C}$ & $80^{\circ} \mathrm{C}$ & $58-73^{\circ} \mathrm{C}$ & $73^{\circ} \mathrm{C}$ & $68^{\circ} \mathrm{C}$ & $70^{\circ} \mathrm{C}$ & $70^{\circ} \mathrm{C}$ & $75^{\circ} \mathrm{C}$ \\
\hline Genome size $(\mathrm{Mb})$ & 1.59 & 3.04 & 1.74 & 1.50 & 1.52 & 1.56 & 1.98 & 1.64 & 1.84 & 1.54 & 1.76 \\
\hline GC-content & 43.3 & 43.8 & 44.0 & 46.9 & 45.2 & 34.8 & 37.1 & 32.8 & 32.0 & 34.9 & 52.1 \\
\hline \multicolumn{12}{|l|}{ MSA Coverage (Mb) } \\
\hline Pomago & $\begin{array}{l}1.45 \\
(90.9 \%)\end{array}$ & $\begin{array}{l}1.72 \\
(56.5 \%)\end{array}$ & $\begin{array}{l}1.52 \\
(87.4 \%)\end{array}$ & $\begin{array}{l}1.40 \\
(93.0 \%)\end{array}$ & $\begin{array}{l}1.41 \\
(92.8 \%)\end{array}$ & $\begin{array}{l}1.28 \\
(81.9 \%)\end{array}$ & $\begin{array}{l}1.55 \\
(78.0 \%)\end{array}$ & $\begin{array}{l}1.51 \\
(91.8 \%)\end{array}$ & $\begin{array}{l}1.62 \\
(88.1 \%)\end{array}$ & $\begin{array}{l}1.36 \\
(87.9 \%)\end{array}$ & $\begin{array}{l}1.40 \\
(79.3 \%)\end{array}$ \\
\hline TBA & $\begin{array}{l}1.38 \\
(86.5 \%)\end{array}$ & $\begin{array}{l}2.02 \\
(66.5 \%)\end{array}$ & $\begin{array}{l}1.52 \\
(87.3 \%)\end{array}$ & $\begin{array}{l}1.40 \\
(93.3 \%)\end{array}$ & $\begin{array}{l}1.40 \\
(91.7 \%)\end{array}$ & $\begin{array}{l}1.15 \\
(73.9 \%)\end{array}$ & $\begin{array}{l}1.57 \\
(78.9 \%)\end{array}$ & $\begin{array}{l}1.52 \\
(92.9 \%)\end{array}$ & $\begin{array}{l}1.55 \\
(84.5 \%)\end{array}$ & $\begin{array}{l}1.31 \\
(84.8 \%)\end{array}$ & $\begin{array}{l}1.36 \\
(77.3 \%)\end{array}$ \\
\hline \multicolumn{12}{|l|}{ WSoP } \\
\hline Pomago & 4.90 & 4.54 & 4.62 & 4.90 & 5.06 & 5.09 & 4.55 & 4.59 & 4.54 & 4.43 & 4.43 \\
\hline TBA & 4.59 & 3.81 & 4.35 & 4.59 & 4.60 & 4.91 & 4.10 & 4.00 & 3.96 & 4.07 & 4.10 \\
\hline \multicolumn{12}{|l|}{ gap ratio } \\
\hline Pomago & 0.130 & 0.108 & 0.109 & 0.105 & 0.105 & 0.125 & 0.120 & 0.130 & 0.120 & 0.118 & 0.105 \\
\hline TBA & 0.091 & 0.090 & 0.089 & 0.092 & 0.093 & 0.096 & 0.093 & 0.089 & 0.091 & 0.085 & 0.084 \\
\hline \multicolumn{12}{|c|}{ de novo Protein Annotation } \\
\hline Homologous ORFs & 685 & 933 & 749 & 695 & 695 & 672 & 806 & 741 & 752 & 744 & 748 \\
\hline Predicted ORFs & 570 & 1394 & 612 & 455 & 499 & 668 & 787 & 686 & 780 & 639 & 495 \\
\hline Min. length (aa) & 40 & 40 & 40 & 45 & 40 & 40 & 40 & 40 & 40 & 40 & 40 \\
\hline Max. length (aa) & 1574 & 1535 & 1566 & 1566 & 1647 & 1563 & 1576 & 1605 & 1579 & 1470 & 1490 \\
\hline \multicolumn{12}{|l|}{ Start codons } \\
\hline TTG (\%) & 6.53 & 8.77 & 5.22 & 4.61 & 8.04 & 9.03 & 13.25 & 14.65 & 14.88 & 13.81 & 12.55 \\
\hline ATG $(\%)$ & 82.71 & 78.51 & 86.55 & 84.43 & 83.25 & 86.34 & 83.24 & 79.12 & 79.18 & 76.64 & 67.34 \\
\hline GTG $(\%)$ & 10.76 & 12.46 & 8.23 & 10.87 & 8.54 & 4.63 & 3.52 & 6.17 & 5.94 & 9.33 & 20.03 \\
\hline \multicolumn{12}{|l|}{ Stop codons } \\
\hline TAA (\%) & 49.24 & 39.32 & 39.09 & 32.35 & 40.20 & 50.45 & 50.97 & 60.62 & 56.46 & 58.06 & 46.98 \\
\hline TAG (\%) & 13.86 & 18.74 & 15.43 & 12.00 & 15.24 & 14.55 & 20.72 & 16.05 & 14.95 & 19.23 & 26.07 \\
\hline TGA $(\%)$ & 36.89 & 41.94 & 45.48 & 55.39 & 44.56 & 35.00 & 28.31 & 23.34 & 28.59 & 22.70 & 26.95 \\
\hline GC-content & 44 & 46.6 & 44.4 & 47.1 & 45.6 & 35.2 & 37.6 & 33.1 & 32.3 & 35.1 & 52.4 \\
\hline \multicolumn{12}{|c|}{ ncRNA Annotation } \\
\hline 5S rRNA & 2 & 3 & 1 & 1 & 2 & 2 & 2 & 2 & 3 & 2 & 3 \\
\hline $16 \mathrm{~S}$ rRNA & 2 & 2 & 1 & 1 & 2 & 2 & 2 & 2 & 3 & 2 & 3 \\
\hline $23 \mathrm{~S}$ rRNA & 2 & 2 & 1 & 1 & 2 & 2 & 2 & 2 & 3 & 2 & 3 \\
\hline tRNA & 44 & 57 & 44 & 44 & 44 & 45 & 40 & 39 & 40 & 43 & 46 \\
\hline RNase P & 0 & 0 & 0 & 0 & 0 & 0 & 1 & 1 & 1 & 1 & 1 \\
\hline 6S RNA & 1 & 2 & 1 & 1 & 1 & 1 & 1 & 1 & 1 & $1 ?$ & $1 ?$ \\
\hline tmRNA & $1(\mathrm{~A})$ & $2(A, B)$ & $1(\mathrm{~A})$ & $1(\mathrm{~A})$ & $1(\mathrm{~A})$ & $1(\mathrm{~A})$ & $1(\mathrm{~B})$ & 1(B) & $1(\mathrm{~B})$ & 1 (B) & $1(\mathrm{~B})$ \\
\hline SRP RNA & 1 & 1 & 1 & 1 & 1 & 1 & 1 & 1 & 1 & 1 & 1 \\
\hline TPP RS & 0 & 1 & 0 & 0 & 0 & 0 & 1 & 0 & 1 & 1 & 1 \\
\hline MOCO & 0 & 0 & 0 & 0 & 0 & 0 & 0 & 0 & 0 & 0 & 1 \\
\hline Cobalamin & 0 & 0 & 0 & 0 & 0 & 0 & 0 & 0 & 0 & 2 & 2 \\
\hline $\mathrm{crcB}$ & 0 & 0 & 0 & 0 & 0 & 2 & 0 & 0 & 0 & 0 & 0 \\
\hline CRISPR & 6 & 12 & 1 & 4 & 6 & 1 & 4 & 13 & 4 & 1 & 8 \\
\hline cas genes & 1 & $1(+1)$ & 1 & 1 & 2 & 0 & $1(+1)$ & 3 & 1 & 0 & (1) \\
\hline GC-content & 65.8 & 62.6 & 61.2 & 63.1 & 63.5 & 54.7 & 60.7 & 57.7 & 57.2 & 61.7 & 63.6 \\
\hline \multicolumn{12}{|l|}{$\begin{array}{l}\text { RNAz Coverage } \\
\text { (nt, } P \geq 0.5 \text { ) }\end{array}$} \\
\hline Pomago & $\begin{array}{l}13574 \\
(0.85 \%)\end{array}$ & $\begin{array}{l}15712 \\
(0.51 \%)\end{array}$ & $\begin{array}{l}13317 \\
(0.76 \%)\end{array}$ & $\begin{array}{l}14213 \\
(0.94 \%)\end{array}$ & $\begin{array}{l}12476 \\
(0.81 \%)\end{array}$ & $\begin{array}{l}12533 \\
(0.80 \%)\end{array}$ & $\begin{array}{l}12067 \\
(0.60 \%)\end{array}$ & $\begin{array}{l}11960 \\
(0.72 \%)\end{array}$ & $\begin{array}{l}12356 \\
(0.67 \%)\end{array}$ & $\begin{array}{l}9969 \\
(0.64 \%)\end{array}$ & $\begin{array}{l}11377 \\
(0.64 \%)\end{array}$ \\
\hline TBA & $\begin{array}{l}25686 \\
(1.61 \%)\end{array}$ & $\begin{array}{l}29909 \\
(0.98 \%)\end{array}$ & $\begin{array}{l}22950 \\
(1.31 \%)\end{array}$ & $\begin{array}{l}21126 \\
(1.40 \%)\end{array}$ & $\begin{array}{l}20751 \\
(1.36 \%)\end{array}$ & $\begin{array}{l}21702 \\
(1.39 \%)\end{array}$ & $\begin{array}{l}22765 \\
(1.14 \%)\end{array}$ & $\begin{array}{l}14022 \\
(0.85 \%)\end{array}$ & $\begin{array}{l}18612 \\
(1.01 \%)\end{array}$ & $\begin{array}{l}17287 \\
(1.12 \%)\end{array}$ & $\begin{array}{l}20367 \\
(1.15 \%)\end{array}$ \\
\hline \multicolumn{12}{|l|}{$\begin{array}{l}\text { RNAz Coverage } \\
\text { (nt, } P \geq 0.9 \text { ) }\end{array}$} \\
\hline Pomago & $\begin{array}{l}4600 \\
(0.28 \%)\end{array}$ & $\begin{array}{l}5091 \\
(0.16 \%)\end{array}$ & $\begin{array}{l}4192 \\
(0.24 \%)\end{array}$ & $\begin{array}{l}5394 \\
(0.35 \%)\end{array}$ & $\begin{array}{l}3862 \\
(0.25 \%)\end{array}$ & $\begin{array}{l}3234 \\
(0.20 \%)\end{array}$ & $\begin{array}{l}4038 \\
(0.20 \%)\end{array}$ & $\begin{array}{l}3828 \\
(0.23 \%)\end{array}$ & $\begin{array}{l}4430 \\
(0.24 \%)\end{array}$ & $\begin{array}{l}4188 \\
(0.27 \%)\end{array}$ & $\begin{array}{l}2990 \\
(0.16 \%)\end{array}$ \\
\hline TBA & $\begin{array}{l}14632 \\
(0.21 \%)\end{array}$ & 16806 & 11833 & 10614 & 10976 & 13341 & $\begin{array}{l}14761 \\
(0.74 \%)\end{array}$ & 6067 & 11072 & 10502 & 14462 \\
\hline
\end{tabular}

Figure $1 \mathrm{General}$ genome features of the Aquificales. The genome size is given as the total number of nucleotides in the assembly. Multiple sequence alignments (MSA) were performed by Pomago and TBA. RNAz was applied to the Pomago- and TBA-derived MSAs. De novo protein annotation is based on statistics from BacProt, neglecting previously reported proteins for Aquificales. Annotation of ncRNAs shows the statistics for identified ncRNAs of known function. Details of CRISPR cassettes, number of repeats and associated proteins can be found in Figure 9 and in the Supplemental Material. TmRNAs are classified into two types (Figure 6). The phylogenetic tree shown at the top of the table is based on the whole genome as well as 16S rRNA analysis of the 11 Aquificales species. It reproduces the results presented in [30-32]. For further information, see Supplemental Material. AAE - A. aeolicus, HVI - Hydrogenivirga sp., HTH - H. thermophilus, HBA - Hydrogenobaculum sp., TAL - T. albus, TRU - T. ruber, PMA - P. marina, SAZ - S. azorense, SSP - Sulfurihydrogenibium sp., DTH - D. thermolithotrophum, TAM - T. ammonificans, RS - Riboswitch, WSoP Weighted sum-of-pairs score [29], * denotes the Hydrogenivirga sp. genome of unfinished assembly.

Protein sequences were clustered using Proteinortho [34] in the blastp+-mode, thus performing a pairwise all-against-all comparison of sequences from different species to derive orthologous relationships. Whenever an orthologous group did not have a member in a certain species, we applied tblastn to the respective genome to complement for potentially incomplete annotations. The highest scoring alignment to an ORF above a fairly high E-value $\leq 10^{-20}$ was added to the initial protein annotation. Finally, 
Proteinortho was applied again using the expanded annotation.

For a high resolution phylogeny within the Aquificales, we created a whole genome alignment using Pomago. The alignment was analyzed using RAxML (v.7.4.2) [58] with a GAMMA model of rate heterogeneity with an estimate on the proportion of invariable sites and 100 rapid bootstraps.

In an additional phylogenetic analysis we used singlecopy orthologous proteins present in at least $50 \%$ of all species in the set (189 groups in 42 species). Each protein group was aligned separately using dialign-tx [59]. Both ends of the group's alignments were cropped to remove leading and tailing gaps. The remaining sequences were concatenated resulting in a 57,260 aa long alignment and applied to RAxML using the LG substitution model [60] as well as the GAMMA model of rate heterogeneity with 100 rapid bootstraps.

The $16 \mathrm{~S}$ rRNA-based phylogeny was computed with Mafft (v.7.017) [61] using the L-INS-i method with 1000 iterations. We used different approaches: (1) Neighbor Joining with the Kimura correction model [62] (1000 bootstraps), (2) Bayesian inference with MrBayes (v.3.1.2) [63] with default parameters, (3) Maximum likelihood with RAxML (v.7.2.8) [64] (200 bootstraps) with the base substitution models (3a) GTRGAMMA (most accurate, 1000 steps) and (3b) GTRCAT for the bootstrapping phase. For all previously mentioned methods the Archaea Methanobacterium sp. AL-21 and Archaeoglobus fulgidus were used as outgroup. As state of the art, we have estimated a tree with (4) Sate (v.2.2.5) [65] (200 iterations). Related sequences were aligned with Mafft and subsequently merged by Muscle (v.3.7) [66]. The tree was computed using RAxML.

\section{dRNA-seq of $A$. aeolicus total cellular RNA}

Transcriptome analysis of $A$. aeolicus was based on cDNA libraries from a differential deep sequencing approach (dRNA-seq) [67,68]. A aeolicus cells, provided by M. Thomm and R. Huber (Regensburg, Germany), were grown for 1 day (late exponential phase) and harvested as described [69]. For preparation of total cellular RNA, we used the hot phenol method [70]: cell pellets were resuspended in extraction buffer $(10 \mathrm{mM}$ sodium acetate $\mathrm{pH} 4.8,150 \mathrm{mM}$ sucrose) and incubated for $10 \mathrm{~min}$ at room temperature with 0.1 volumes of lysozyme (20 mg/ml, Roth, Karlsruhe, Germany). SDS was added to a final concentration of $1 \%$ followed by vigorous vortexing. After addition of 1 volume phenol (preheated to $65^{\circ} \mathrm{C}$ ) and vortexing, the mixture was incubated for $5 \mathrm{~min}$ at $65^{\circ} \mathrm{C}$, then cooled on ice for $5 \mathrm{~min}$, and centrifuged for $30 \mathrm{~min}$ at $4^{\circ} \mathrm{C}$ and $8200 \mathrm{~g}$. Phenol extraction was repeated, followed by chloroform $(1+1)$ extraction and ethanol precipitation. Finally, the DNA was digested with $10 \mathrm{U}$ Turbo DNase (Ambion, Austin, USA) for $30 \mathrm{~min}$ at $37^{\circ} \mathrm{C}$, followed by addition of another $10 \mathrm{U}$ DNase and incubation for another $30 \mathrm{~min}$ at $37^{\circ} \mathrm{C}$. Subsequently, the RNA was subjected to phenol/chloroform extraction and ethanol precipitation. After redissolving the RNA in double-distilled water, its concentration was determined by UV spectroscopy. Before cDNA library construction, the RNA was split into two fractions; one fraction was treated with Terminator 5' P-dependent exonuclease (Epicentre, Madison, USA) for depletion of transcripts carrying a 5'-monophosphate. Both fractions were treated with Tobacco Acid Phosphatase (TAP) before 5'-linker ligation, poly $(\mathrm{A})$ tailing and conversion into cDNA (vertis Biotechnologie AG, Freising, Germany). The cDNA libraries were then sequenced on a Roche FLX sequencer and resulted in the (-) -library with 25,816 reads and the $(+)$-library $(33,697$ reads) containing the enriched primary transcripts.

\section{Detection of novel ncRNAs}

We used the IGB (Integrated Genome Browser) [71] to visualize the following features of A. aeolicus: (1) nucleotide sequence; (2) local GC-content (for each nucleotide $15 \mathrm{nt}$ on both sides were included for the calculation of GC-content); (3) protein genes annotated by NCBI [72] and BacProt; (4) locally stable secondary structures: calculation was performed with RNALfold with options $-d 2$ and $-L 120$ for both strands with a maximum base-pair span of 120 nucleotides. Sequences with local structures of fewer than 50 nt were discarded. For the prediction of thermodynamically stable RNA structures, each sequence was shuffled 1000 times while preserving the dinucleotide frequencies; to classify extraordinarily stable RNA secondary structures, we chose to use a Z-score cutoff of -3.0 ( top 5\% of stable structures); (5) conserved regions among the Aquificales: with default parameters of TBA and Pomago we aligned 11 genomes; the TBA alignment was projected to each of the reference genomes; coverage, WSoP and gap ratio are given in Figure 1 ; (6) novel ncRNAs: novel ncRNA candidates were predicted using RNAz. We used rnazWindow.pl -min-seqs $=4$ and $\mathrm{RNAz}-\mathrm{n}-\mathrm{b}-\mathrm{p} \quad 0.5$ on the alignments of Pomago and TBA. As rnazWindow.pl assumes lower case nucleotides to be masked, the alignments were converted to upper case letters beforehand; (7) dRNA-seq: cDNA libraries were mapped with segemehl (v.0.0.9.3) [73]

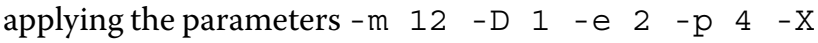
8 -A 90 - E 5.0.

\section{Northern blot experiments Total RNA preparation}

Total RNA was prepared from cell pellets using the hot phenol method as described [74]. 


\section{Positive and negative controls}

The positive and the negative controls for the Northern blot experiments were synthesized by in vitro transcription using the "TranscriptAid T7 High Yield Transcription Kit" (Thermo Scientific, Germany), according to the protocol supplied by the manufacturer. PCR products generated with the "Long PCR Enzyme Mix" (Thermo Scientific) served as templates for in vitro transcription. As positive controls for the antisense tRNA blots, chemically synthesized RNA oligonucleotides from "Integrated DNA Technologies" (IDT, Belgium) were used (for sequences, see Supplemental Material). RNA oligonucleotides were 5'-phosphorylated before gel electrophoresis. The in vitro transcribed full-length sense tRNAs (generated from PCR products) were used as negative controls for the Northern blots of antisense tRNAs.

\section{Digoxigenin and $L N A$ probes}

For the Northern blot detection internally digoxigeninlabeled probes were transcribed using the DIG RNA Labeling Mix (Roche Diagnostics, Germany) as described [74]. The antisense tRNA transcripts were detected with chemically synthesized 5'-digoxigenin-labeled DNA/LNA mixmer probes (Exiqon, Denmark; for sequences, see Supplemental Material).

\section{5'-Phosphorylation of RNA oligonucleotides}

$67 \mathrm{ng} / \mu \mathrm{l}$ RNA oligonucleotide, $2.5 \mathrm{mM}$ DTT, $2 \mathrm{mM}$ ATP and $10 \mathrm{U}$ T4 polynucleotide kinase (T4 PNK; Thermo Scientific) were incubated in $1 \times \mathrm{T} 4$ PNK buffer (Thermo Scientific) in a volume of $15 \mu \mathrm{l}$ for $1 \mathrm{~h}$ at $37^{\circ} \mathrm{C}$, followed by transfer to and storage at $-20^{\circ} \mathrm{C}$.

\section{Electrophoresis}

RNAs were separated on $8 \%$ or $10 \%$ denaturing ( $8 \mathrm{M}$ urea) PAA gel with $1 \times \mathrm{TBE}$ as electrophoresis buffer [74].

\section{Blotting, crosslinking, hybridization and detection}

RNA blotting, hybridization (EDC crosslinking or baking at $80^{\circ} \mathrm{C}$ for $40 \mathrm{~min}$ ) and immunological detection were performed as described [74], except that RNA blotting was carried out at $0.36 \mathrm{~mA} / \mathrm{cm}^{2}$ overnight. Prehybridization and hybridization were performed at $68^{\circ} \mathrm{C}$ (except for $50^{\circ} \mathrm{C}$ in the case of antisense tRNA 44) using $12 \mathrm{ml}$ hybridization solution. $3.5 \mu \mathrm{l}$ of in vitro transcribed, internally digoxigenin-labeled probe were added for overnight hybridization. $300 \mathrm{pmol}$ of chemically synthesized, 5'digoxigenin-labeled DNA/LNA mixmer probe were used for Northern detection of antisense tRNAs. Blotted membranes were stored at room temperature.

\section{In vitro transcripts, probes and primers}

Further details on in vitro transcripts, probes and primers are listed in the Supplemental Material.

\section{Results and discussion}

\section{Genome analysis - general observations}

The genomes of the Aquificales range from $1.50 \mathrm{Mb}$ (T. albus) to $1.98 \mathrm{Mb}$ (P. marina), thus being at the lower limit of bacterial genomes ranging in size from 0.14 to $14.38 \mathrm{Mb}$ with a mean of $\sim 4 \mathrm{Mb}$ [75]. The current annotation file of Hydrogenivirga sp. contains $3.04 \mathrm{Mb}$, which is considerably larger than the genome size of the other Aquificales, which might be an assembly artefact as discussed later.

Aquificales are known to be AT-rich with a GC-content of about 43\% [72,76]. In Hydrogenobaculum sp., Sulfurihydrogenibium sp. and S. azorense even only one-third of the nucleotides are guanine or cytosine. For T. ammonificans an atypically high GC-content of more than $50 \%$ was observed.

Between 6.5\% (S. azorense) and 28.5\% (Hydrogenobaculum sp.) of the genomes were found to be unique to each member bacterium (Figure 1). The comparatively low coverage of Hydrogenivirga sp. is due to the currently assembled genome being almost twice as long as those of other Aquificales. $10.5 \%$ to $13.0 \%$ of the Pomago alignment, resp. $8.4 \%$ to $9.6 \%$ of the TBA alignment, consist of gaps. According to the WSoP each nucleotide from the alignment is conserved on average in slightly less than half of the other 10 species (4.43 to 5.09 out of 11 and 3.81 to 4.91 out of 11, for Pomago and TBA, respectively) indicating that the genomes diverged relatively fast. Genomic rearrangements among the Aquificales, underlining the diversity, can be seen in an overview of the Pomago alignment in the Supplemental Material.

\section{Extended annotation of proteins}

We extended the original NCBI annotation of proteins of the Aquificales de novo using BacProt, revealing a number of additional proteins (Table 1). Since a large fraction of proteins are hypothetical or of unknown function, we added for each species a second row which exclusively depicts those with an associated function. The annotations of NCBI and BaCProt were merged to generate an extended annotation of protein genes in the Aquificales.

We added between $0.7 \%$ of $H$. thermophilus (1352/1343) and $10.6 \%$ of $A$. aeolicus (1002/897) protein-coding genes to the NCBI annotation.

For all proteins annotated by BacProt, we extracted the Shine-Dalgarno and Pribnow box (-10 box) motifs (see Figure 2) in order to facilitate the assignment of novel Aquificales-specific proteins. The Shine-Dalgarno sequence is rather conserved (GGAGG, but always NGAGN). In contrast, the Pribnow box is recognizable but less conserved, indicating more sequence variations among promoters. With the appropriate covariance models we searched for species-specific novel proteins and listed them as predicted proteins in the Supplemental Material. 
Table 1 Protein annotations

\begin{tabular}{|c|c|c|c|c|c|c|c|c|}
\hline & NCBI & BacProt & Equal & Start shifted & End shifted & NCBI only & BacProt only & Extended \\
\hline \multirow[t]{2}{*}{ AAE } & 1560 & 1255 & 954 & 116 & 124 & 366 & 61 & 1621 \\
\hline & 897 & 685 & 475 & 51 & 54 & 317 & 105 & 1002 \\
\hline \multirow[t]{2}{*}{ DTH } & 1513 & 1383 & 1092 & 86 & 105 & 230 & 100 & 1613 \\
\hline & 1115 & 744 & 561 & 58 & 74 & 422 & 51 & 1166 \\
\hline \multirow[t]{2}{*}{ HBA } & 1629 & 1340 & 1040 & 119 & 126 & 344 & 55 & 1684 \\
\hline & 1063 & 672 & 500 & 62 & 68 & 433 & 42 & 1105 \\
\hline \multirow[t]{2}{*}{ HTH } & 1893 & 1361 & 1069 & 111 & 129 & 584 & 52 & 1945 \\
\hline & 1343 & 749 & 594 & 62 & 84 & 603 & 9 & 1352 \\
\hline \multirow[t]{2}{*}{ PMA } & 2051 & 1593 & 1286 & 129 & 122 & 514 & 56 & 2107 \\
\hline & 1494 & 806 & 629 & 84 & 76 & 705 & 17 & 1511 \\
\hline \multirow[t]{2}{*}{ SAZ } & 1723 & 1427 & 1190 & 90 & 99 & 344 & 48 & 1771 \\
\hline & 1321 & 741 & 601 & 50 & 73 & 597 & 17 & 1338 \\
\hline \multirow[t]{2}{*}{ SSP } & 1722 & 1532 & 1225 & 76 & 108 & 313 & 123 & 1845 \\
\hline & 1145 & 752 & 573 & 38 & 70 & 464 & 71 & 1216 \\
\hline \multirow[t]{2}{*}{ TAL } & 1593 & 1145 & 903 & 93 & 127 & 470 & 22 & 1615 \\
\hline & 1144 & 691 & 514 & 59 & 85 & 486 & 33 & 1177 \\
\hline \multirow[t]{2}{*}{ TAM } & 1814 & 1243 & 1014 & 90 & 99 & 611 & 40 & 1854 \\
\hline & 1176 & 748 & 575 & 60 & 63 & 478 & 50 & 1226 \\
\hline \multirow[t]{2}{*}{$\mathrm{HVI}$} & 3808 & 2327 & 1537 & 302 & 306 & 1663 & 182 & 3990 \\
\hline & 1960 & 933 & 595 & 102 & 92 & 1171 & 144 & 2104 \\
\hline
\end{tabular}

Annotations obtained with NCBI (first column, bold font) and those identified with BacProt (second column) lead to an extended current annotation of Aquificales (last column, bold font). In the second lines, hypothetical proteins were removed. Equal - proteins equally identified by BaCProt and NCBI; Start/End shifted proteins identified by BaCProt and NCBI vary in length (only 5' or 3'); NCBI/BaCProt only - proteins identified only by NCBI/BaCProt. All gff files are available in the Supplemental Material. Species abbreviations as in Figure 1.

An overview of the codon usage of $A$. aeolicus is shown in Table 2. Complete data on all codon usage tables and mono/dinucleotide distributions are provided in the Supplemental Material. We observe a disproportionate usage of certain triplets: isoleucine is mostly (63\%) encoded by AUA, tyrosine by UAC (82\%) and histidine by CAC (84\%). The four arginine codons with a cytosine at the first position of the triplet are rarely used, compared to the two adenine-containing triplets $(9 \% / 91 \%)$.

\section{Homology search and annotation of known ncRNAs}

A search for ncRNA candidates with RNAz [77] predicted a relatively constant fraction of the genome to code for ncRNAs (between $0.36 \%$ for $S$. azorense and $0.91 \%$ for A. aeolicus). Besides the well-known and described rRNAs and tRNAs, only a handful of other wide-spread ncRNAs were detected (Figure 1).

\section{rRNA operons}

Most of the Aquificales genomes have two rRNA operons (Figure 1). H. thermophilus and T. albus appear to harbor only one operon. The genomes of T. ammonificans and Sulfurihydrogenibium sp. contain three operons, whereas Hydrogenivirga sp. appears to have two 16S, two 23S and three $5 \mathrm{~S}$ rRNA genes.

\section{tRNAs}

With the exception of Hydrogenivirga sp. (see below), tRNAscan identified between 39 (S. azorense) and 46 tRNAs (T. ammonificans) per Aquificales species. With SPLITS and ARAGORN no split tRNAs were found.

All possible codons are utilized in the Aquificales (see Table 2 for $A$. aeolicus, and Supplemental Material for other Aquificales), but the number of tRNA genes is reduced to a minimum in contrast to reference bacteria such as $E$. coli which encodes multiple copies of many tRNA isoacceptors.

Figure 3 shows nearly no tRNA with $5^{\prime}-\mathrm{A}$ in the anticodon and only half of the Aquificales have some anticodons with 5'-C, where the non-Aquificaceae apparently favored the reduction of such tRNA genes (Figure 4). Important tRNA modification enzymes (TadA - tRNA adenosine deaminase and TilS - tRNA-Ile lysidine synthetase) are encoded in Aquificales and X-ray structures of TadA and TilS from $A$. aeolicus have been reported $[78,79]$. TadA converts $A$ residues in the 5'-position of certain tRNA anticodons to inosine to expand wobble decoding, and TilS converts the $5^{\prime}-\mathrm{C}$ residue in the CAU anticodon of specific tRNA-Ile molecules to lysidine (2-lysyl cytidine; abbreviated as $L$ or $k^{2} C$ ) to decode 5'AUA (Ile) codons instead of 5'-AUG (Met) codons [80]. 


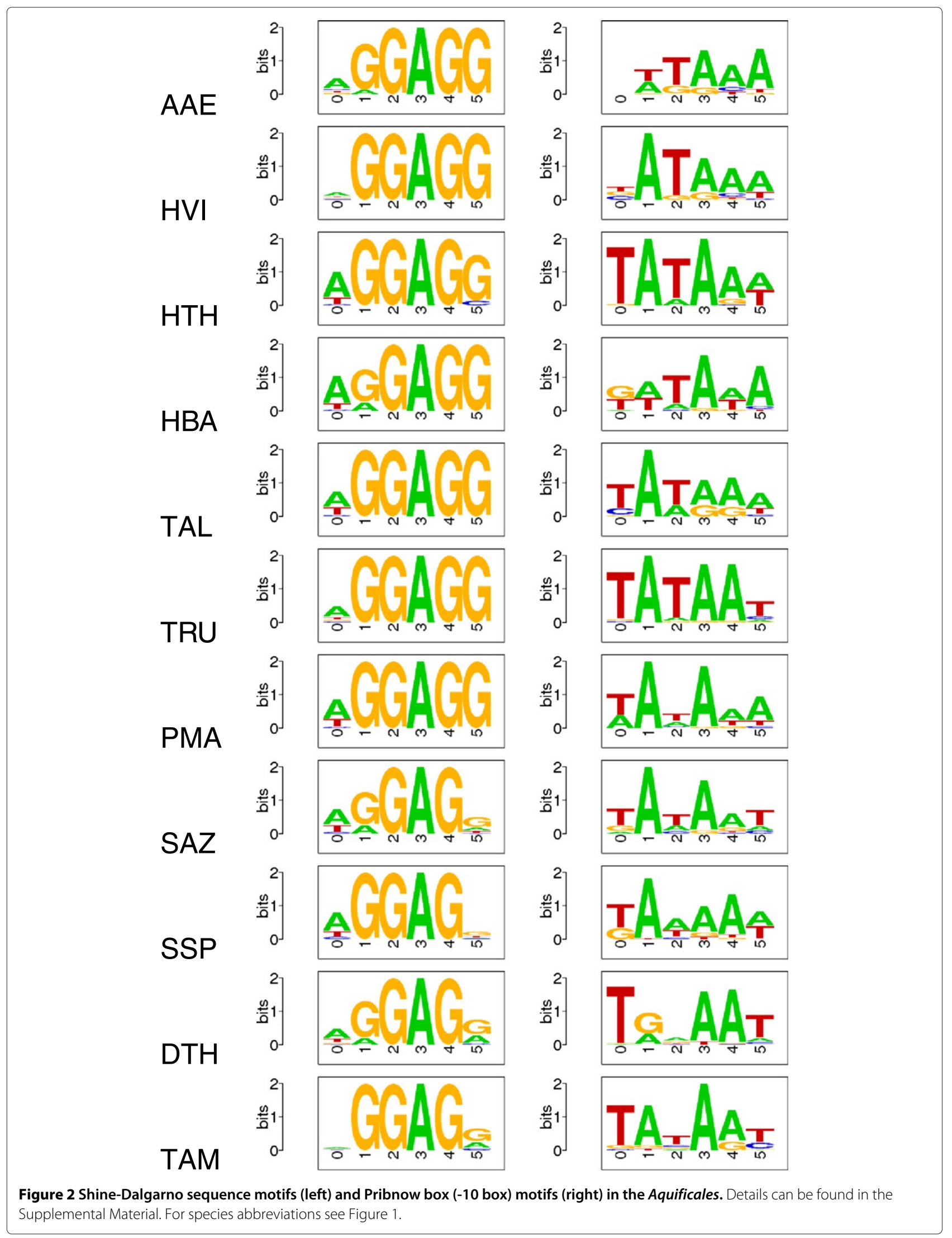


Table 2 Codon usage of $A$. aeolicus

\begin{tabular}{|c|c|c|c|c|c|c|c|c|c|c|c|c|c|c|c|c|c|}
\hline & Codon & aa & $\%$ & Fraction & Codon & aa & $\%$ & Fraction & Codon & aa & $\%$ & Fraction & Codon & aa & $\%$ & Fraction & \\
\hline & UUU & Phe (F) & 2.9 & 0.56 & UCU & $\operatorname{Ser}(S)$ & 0.9 & 0.18 & UAU & $\operatorname{Tyr}(Y)$ & 0.8 & 0.18 & UGU & Cys (C) & 0.4 & 0.49 & U \\
\hline & UUC & Phe (F) & 2.3 & 0.44 & UCC & $\operatorname{Ser}(S)$ & 1.3 & 0.27 & UAC & $\operatorname{Tyr}(Y)$ & 3.4 & 0.82 & UGC & Cys (C) & 0.4 & 0.51 & C \\
\hline & UUA & Leu (L) & 1.7 & 0.16 & UCA & $\operatorname{Ser}(S)$ & 0.7 & 0.15 & UAA & stop & 0.1 & 0.49 & UGA & stop & 0.1 & 0.37 & A \\
\hline & UUG & Leu (L) & 0.8 & 0.08 & UCG & $\operatorname{Ser}(S)$ & 0.4 & 0.07 & UAG & stop & 0 & 0.14 & UGG & $\operatorname{Trp}(\mathrm{W})$ & 0.9 & 1 & G \\
\hline & CUU & Leu (L) & 2.7 & 0.25 & $\mathrm{CCU}$ & Pro (P) & 1.1 & 0.26 & $C A U$ & $\mathrm{His}(\mathrm{H})$ & 0.3 & 0.16 & CGU & $\operatorname{Arg}(R)$ & 0.2 & 0.03 & U \\
\hline & CUC & Leu (L) & 3.1 & 0.3 & CCC & Pro (P) & 1.8 & 0.42 & CAC & $\mathrm{His}(\mathrm{H})$ & 1.3 & 0.84 & CGC & $\operatorname{Arg}(R)$ & 0.1 & 0.03 & C \\
\hline & CUA & Leu (L) & 0.8 & 0.07 & CCA & Pro (P) & 0.6 & 0.14 & CAA & $\mathrm{G} \ln (\mathrm{Q})$ & 0.7 & 0.35 & CGA & $\operatorname{Arg}(R)$ & 0.1 & 0.01 & A \\
\hline & CUG & Leu (L) & 1.4 & 0.14 & CCG & Pro (P) & 0.7 & 0.18 & CAG & $\mathrm{G} \ln (\mathrm{Q})$ & 1.3 & 0.65 & CGG & $\operatorname{Arg}(R)$ & 0.1 & 0.02 & G \\
\hline & $A \cup U$ & Ile (I) & 1.7 & 0.23 & $\mathrm{ACU}$ & $\operatorname{Thr}(\mathrm{T})$ & 1 & 0.23 & AAU & Asn (N) & 1.1 & 0.3 & $A G U$ & $\operatorname{Ser}(S)$ & 0.8 & 0.16 & U \\
\hline & $A \cup C$ & Ile (I) & 1 & 0.13 & ACC & Thr (T) & 1.2 & 0.27 & AAC & Asn (N) & 2.5 & 0.7 & AGC & $\operatorname{Ser}(S)$ & 0.8 & 0.17 & C \\
\hline & $A \cup A$ & Ile (I) & 4.6 & 0.63 & ACA & Thr (T) & 0.9 & 0.21 & AAA & Lys (K) & 4.4 & 0.48 & AGA & $\operatorname{Arg}(\mathrm{R})$ & 1.9 & 0.38 & A \\
\hline & AUG & Met (M) & 1.8 & 1 & ACG & Thr (T) & 1.2 & 0.29 & AAG & Lys (K) & 4.8 & 0.52 & AGG & $\operatorname{Arg}(\mathrm{R})$ & 2.6 & 0.53 & G \\
\hline & GUU & Val (V) & 3 & 0.38 & $\mathrm{GCU}$ & Ala (A) & 1.6 & 0.26 & GAU & Asp (D) & 1.6 & 0.37 & GGU & Gly (G) & 1.6 & 0.23 & U \\
\hline & GUC & Val (V) & 0.9 & 0.11 & GCC & Ala (A) & 1.3 & 0.21 & GAC & Asp (D) & 2.7 & 0.63 & GGC & Gly (G) & 0.9 & 0.12 & C \\
\hline & GUA & Val (V) & 2.5 & 0.32 & GCA & Ala (A) & 1.7 & 0.29 & GAA & Glu (E) & 6.2 & 0.65 & GGA & Gly (G) & 3.4 & 0.5 & A \\
\hline & GUG & Val (V) & 1.5 & 0.19 & GCG & Ala (A) & 1.4 & 0.24 & GAG & Glu (E) & 3.3 & 0.35 & GGG & Gly (G) & 1 & 0.15 & G \\
\hline
\end{tabular}

Codon usage is based on 1,255 protein-coding genes comprising 431,072 codons. Codon usage of other Aquificales can be viewed in the Supplemental Material. aa - amino acid; the fraction of a particular amino acid encoded by the respective codon is given ( 1 for Trp encoded by a single codon).

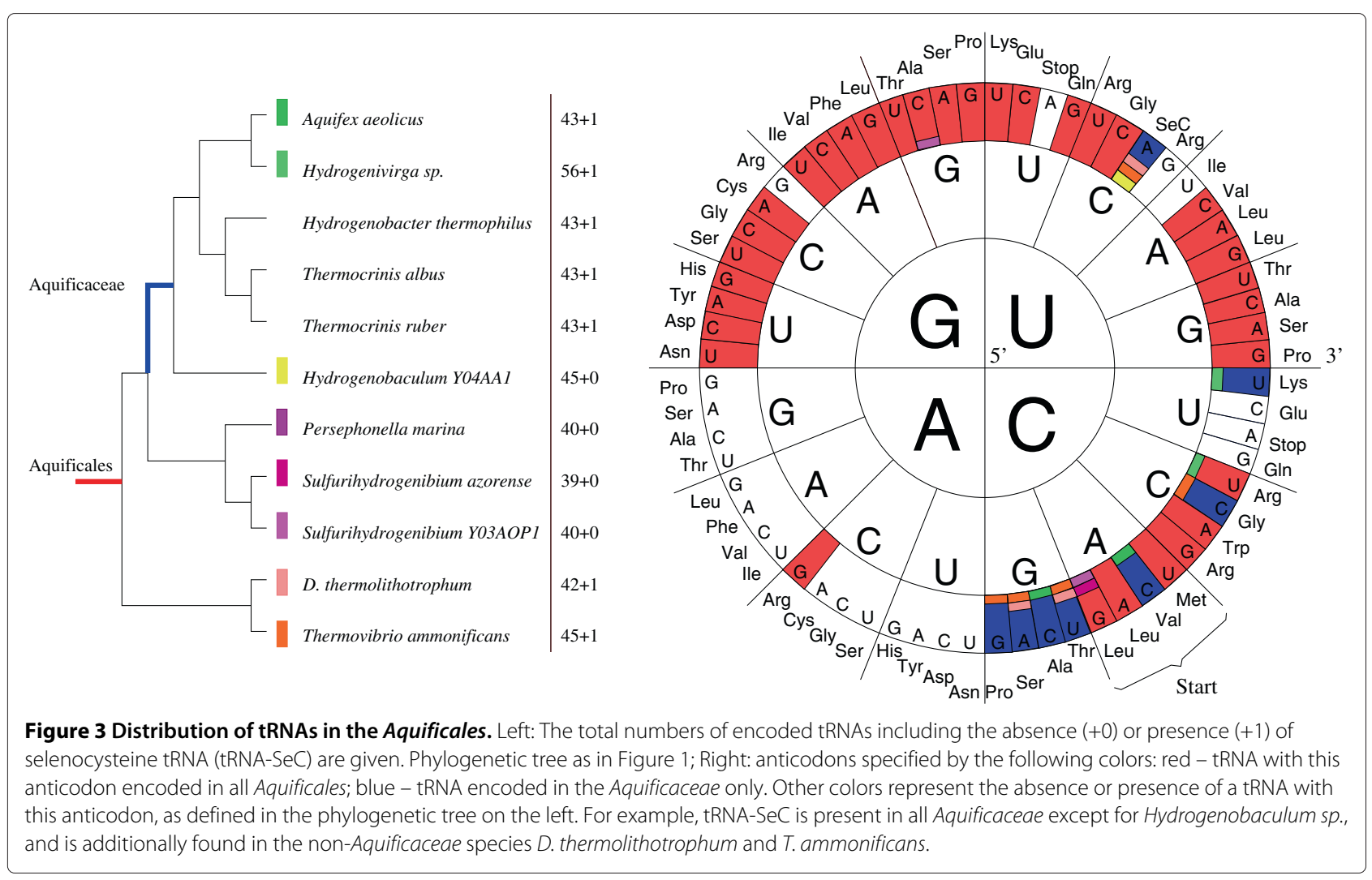




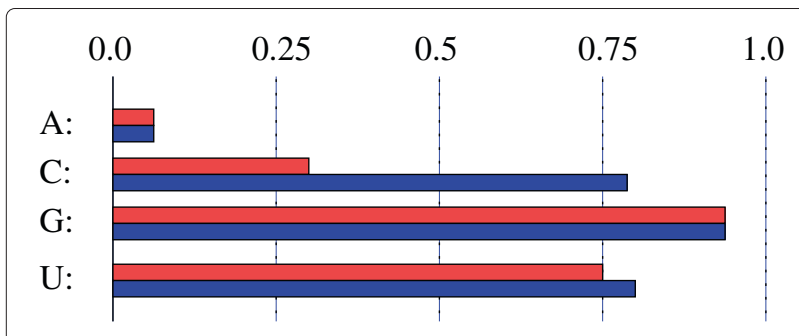

Figure 4 The distribution of the $5^{\prime}$ (wobble) position of a tRNA anticodon in all Aquificales (red) versus Aquificaceae only (blue) is U: $0.75 / 0.80 \%, \mathrm{G}: 0.93 / 0.94 \%, \mathrm{C}: 0.30 / 0.78 \%, \mathrm{~A}: 0.06 / 0.06 \%$.

Non-Aquificaceae show a low percentage of wobble $\mathrm{C}$.

Without this posttranscriptional modification, decoding of isoleucine AUA codons would be impossible [81-83]. Selenocysteine-specific tRNAs decoding 5'-UGA are present in the Aquificaceae (except for Hydrogenobaculum $s p$.) and in the Desulfurobacteriaceae (T. ammonificans and $D$. thermolithotrophum), but are absent from the Hydrogenothermaceae (P. marina, S. azorense, Sulfurihydrogenibium sp.; see Figure 3). The Aquificaceae (except Hydrogenivirga sp.), in contrast to the other Aquificales or mesophiles such as E. coli or B. subtilis, encode the lysine isoacceptor with the anticodon 5'-CUU to decode the AAG codon.

\section{RNase $P$}

The catalytic RNA subunit of the tRNA processing endoribonuclease RNase $\mathrm{P}$ was previously identified in P. marina and S. azorense [84]. Additionally, RNase P RNAs were easily identified here with Bcheck in Sulfurihydrogenibium sp., T. ammonificans and D. thermolithotrophum. In the Aquificaceae, RNase P RNA candidates were neither detected with Bcheck, rnabob nor by manual in silico search methods using cDNA libraries of $A$. aeolicus. This is consistent with the negative results of previous searches for RNase P RNA in A. aeolicus $[85,86]$.

All identified RNase P RNAs lack the P18 element, which appears to be a general feature of type A RNase P RNAs in the Hydrogenothermaceae and Desulfurobacteriaceae. The Sulfurihydrogenibium sp., T. ammonificans and $D$. thermolithotrophum RNAs differ from their P. marina and S. azorense counterparts by a weaker L9P1 tertiary contact (L9 5'-GYAA tetraloop docking on an $\mathrm{A}-\mathrm{U} / \mathrm{G}-\mathrm{C}$ tandem bp instead of a G-C/G-C tandem which is a hallmark of RNase P RNAs from thermophiles $[84,87])$. Other differences are: (1) very short P12 stems in T. ammonificans and D. thermolithotrophum, (2) particularly weak P17 stems in Sulfurihydrogenibium sp. and D. thermolithotrophum, (3) a destabilized L8-P4 interaction, a destabilized P14 helix, but a stabilized L14-P8 interaction in T. ammonificans. For details, see RNase P RNA 2D structures in the Supplemental Material.

\section{S RNA}

Bacterial 6S RNAs, about 200 nt in length, form a rodshaped secondary structure with a central bulge region flanked by largely helical arms on both sides. Their structure is thought to mimic the structure of an open DNA promoter [88,89]. 6S RNAs bind to the housekeeping RNA polymerase holoenzyme to block transcription at DNA promoters, primarily upon entry of cells into stationary growth phase. When nutrients are resupplied (including NTPs), RNA polymerase massively synthesizes transcripts (so-called product RNAs - pRNAs) on 6S RNA as template, which lead to a structural rearrangement of 6S RNA and release of RNA polymerase. Thus, 6S RNA is a fast riboregulator that makes RNA polymerase instantly available for a new exponential growth when nutrients are resupplied [68,90-93].

In $A$. aeolicus the $6 \mathrm{~S}$ RNA was clearly identified via an experimental RNomics approach [85]. 6S RNA candidates in the other Aquificales were predicted computationally using the Rfam covariance model and, as expected, vary substantially in primary, but less in secondary structure. For Hydrogenivirgia we found two copies. Predicted 6S RNAs for T. ammonificans and D. thermolithotrophum remain candidates since they differ substantially from those of other Aquificales.

The RNAalifold consensus structure for the 6S RNA candidates from all other Aquificales analyzed here is shown in the Supplement. Individual RNAfold predictions (see Supplemental Material for details) support the notion that they are bona fide 6S RNAs.

In the case of $A$. aeolicus $6 \mathrm{~S}$ RNA, we proposed that formation of a "central bulge collapse" helix (Figure 5-Top, [85]) is the major component of the pRNA-induced rearrangement of this 6S RNA structure [90]. If at all, or to which extent, the adjacent hairpin structure forms in the pRNA-rearranged structure remains to be investigated. For the eight other 6S RNA candidates (Figure 5), we predicted rod-shaped structures with a destabilized central region that is not necessarily purely single-stranded (see Supplemental Material for further details). According to our proposals, pRNAs would start with a $G$ residue in the Aquificaceae, whereas those of the Hydrogenothermaceae (P. marina, S. azorense and Sulfurihydrogenibium sp.) would initiate with an $A$ residue.

\section{tmRNA}

In bacteria, stalling of translating ribosomes on truncated mRNAs is rescued through action of the dual-function transfer-messenger RNAs (tmRNAs) [94,95]. The tRNAlike domain is present and highly conserved in all Aquificales. An architectural feature of tmRNAs is their intricate structure consisting of four pseudoknots. Interestingly, we found two different types of tmRNAs, introduced here as type A (present in the Aquificaceae) and B 


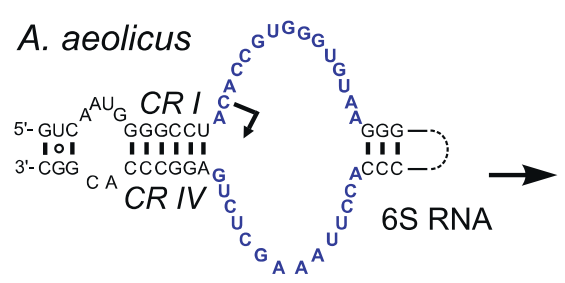

H. thermophilus

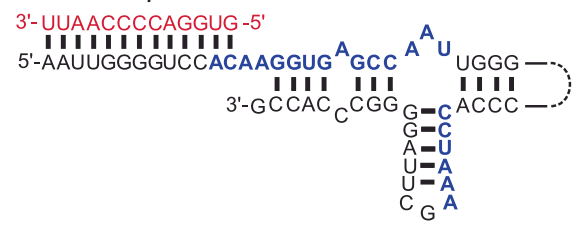

Hydrogenobaculum $s p$.

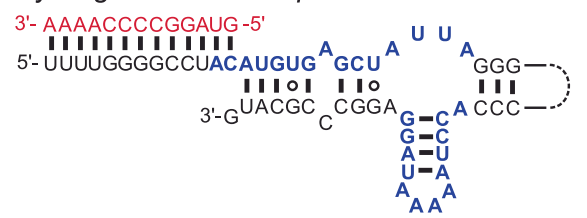

T. ruber
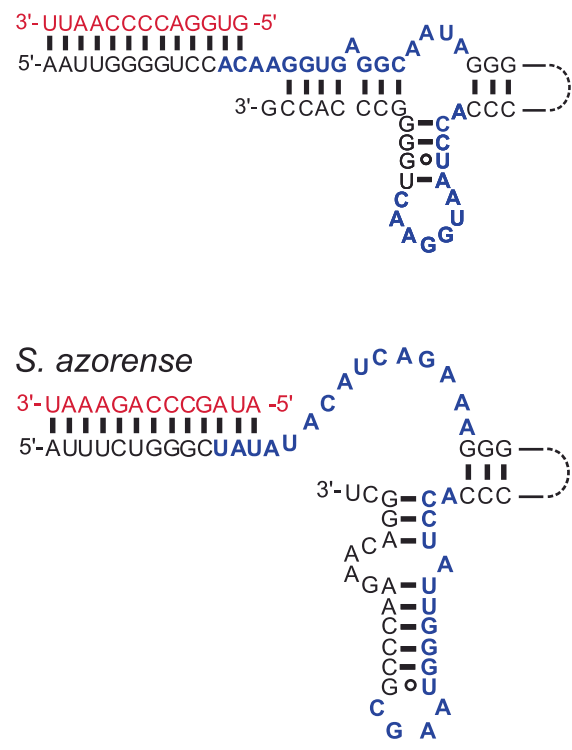

\section{PRNA}

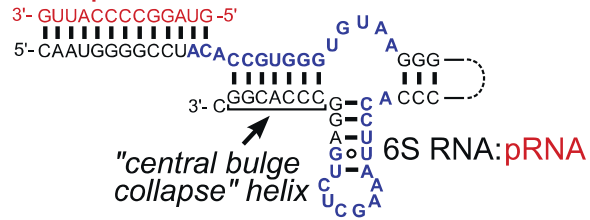

Hydrogenivirga sp.

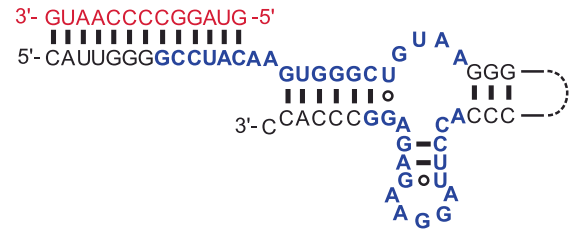

T. albus

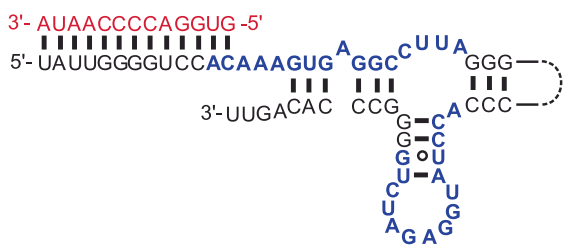

P. marina

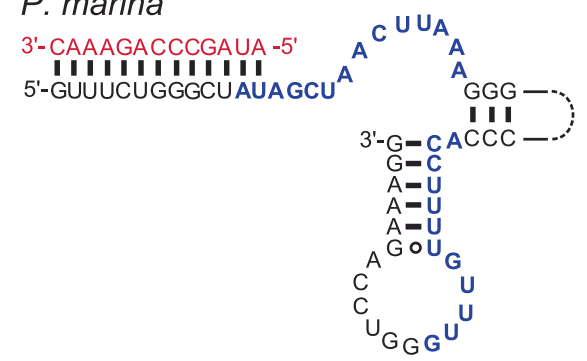

Sulfurihydrogenibium

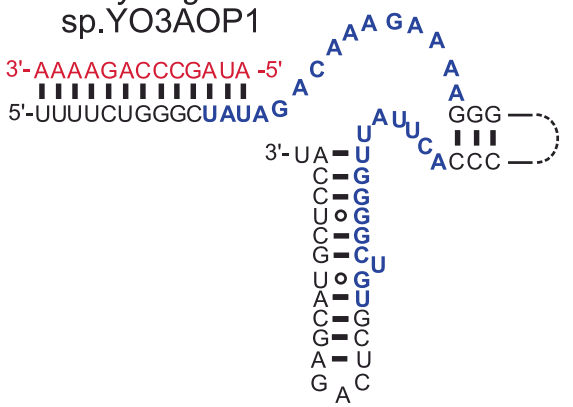

Figure 5 Aquificales $6 \mathrm{~S}$ RNAs: predicted pRNA transcription initiation sites, and pRNA-induced structural rearrangements of $6 \mathrm{~S}$ RNAs. Top: A. aeolicus 6S RNA; this 6S RNA was experimentally verified [85] and the pRNA transcription start site identified by deep sequencing (unpublished results); nucleotides of the central bulge region are marked in blue; during PRNA transcription on 6S RNA as template, the endogenous helix is disrupted, leading to the formation of new base-pairing interactions. Here, a 6S RNA hybrid with a pRNA 13-mer (red) is shown on the right; the proposed rearranged structure of the central 6S RNA region [90] has not yet been proven experimentally. Proposed structures of the central bulge regions and their pRNA-induced rearrangements of the other eight Aquificales 6S RNA candidates: rearranged structures upon duplex formation with putative pRNA 13-mers; the pRNA initiation sites are proposed on the basis of resemblance to A. aeolicus 6S RNA. For more details, see Supplemental Material. 


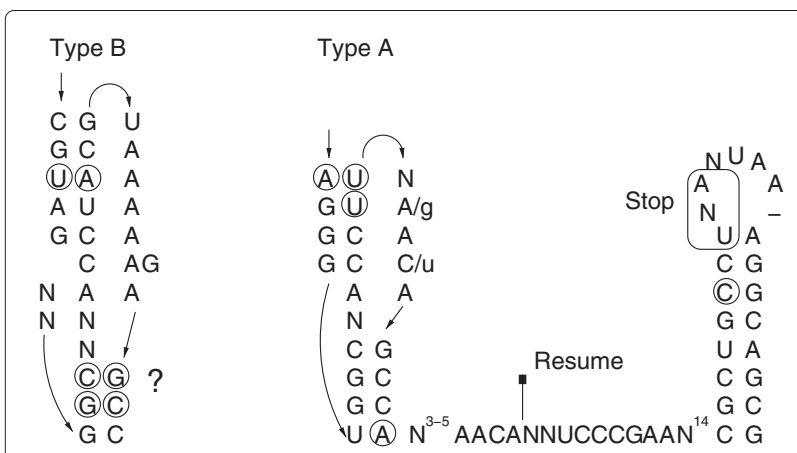

Figure 6 Pseudoknot 1 (pk1) of tmRNAs type $A$ and $B$. Formation of the lower stem of pk1 is questionable. Circled nucleotides represent positions of compensatory mutations. The question mark shows an unclear interaction of two (in one case three) base pairs.

(specific to Hydrogenothermaceae and Desulfurobacteriaceae). This classification is based on the observation that the lower stem of pseudoknot 1 (pk1) involves 4-5 bp in type A tmRNAs, but only $2-3 \mathrm{bp}$ in type B variants (Figure 6, Supplemental Material). Pk1 is critical for tmRNA function and binds near the ribosomal decoding site [95]. Mutational analysis of E. coli tmRNA revealed that mutations disrupting the upper stem of pk1 are not tolerated, whereas the outer two base pairs of the lower stem (Figure 6) can be disrupted (resulting in a 3-bp stem) without loss of function [95]. On the other hand, the tmRNA of another thermophile, Thermotoga maritima, has a lower pk1 stem expanded to $7 \mathrm{bp}$ [96]. This raises the question if the Aquificales type B tmRNAs, for which only a 2-bp lower pk1 stem is predicted (Sulfurihydrogenibium sp., P. marina and S. azorense), are still able to form this pseudoknot, or if the weakness or absence of this stem is compensated for by e.g. tmRNA ligand interactions that are idiosyncratic to the Aquificales encoding a type B tmRNA.

The messenger RNA-like regions (MLR), which are in close vicinity of pk1, encode tag preptides of 10 amino acids, with subphyla-specific signatures (Figure 7). For example, all Aquificaceae and Hydrogenothermaceae tmRNAs code for a proline at the second position, which is alanine in the Desulfurobacteriaceae. The genome of Hydrogenivirga $s p$. appears to encode both types of tmRNAs (type A and B). Whether this reflects a genuine tmRNA gene duplication rather than a genome contamination or assembly artefact remains to be clarified (see below).

Furthermore, Hydrogenobaculum sp. carries a 78-nt hairpin-like insertion in the pseudoknot $4(\mathrm{pk} 4)$ region, which however is compatible with formation of $\mathrm{pk} 4$ (Figure 8). Such a long extension within tmRNAs has been not reported yet.

\section{CRISPR system}

For each member of the Aquificales we could identify at least one locus of clustered interspaced short palindromic repeat sequences (CRISPRs), which are involved in an immunity against viruses and plasmids [97]. Although the Aquificales have very compact genomes, the number of identified CRISPR clusters varied from one to thirteen (Figure 1), indicating the presence of thermostable viruses in extreme environments as reported for Archaea [98]. The number of CRISPR clusters does not seem to be clade-specific. Also, the number of repeats in a cluster varies strongly. For example, in T. albus we found in total four CRISPR systems containing 36, 41, 57 and 63 repeats, whereas in $A$. aeolicus the five CRISPR loci only had four to five repeats. For some, but not all of the CRISPR clusters, we could detect associated cas genes (Figure 9). The exact numbers of detected CRISPR clusters and Cas

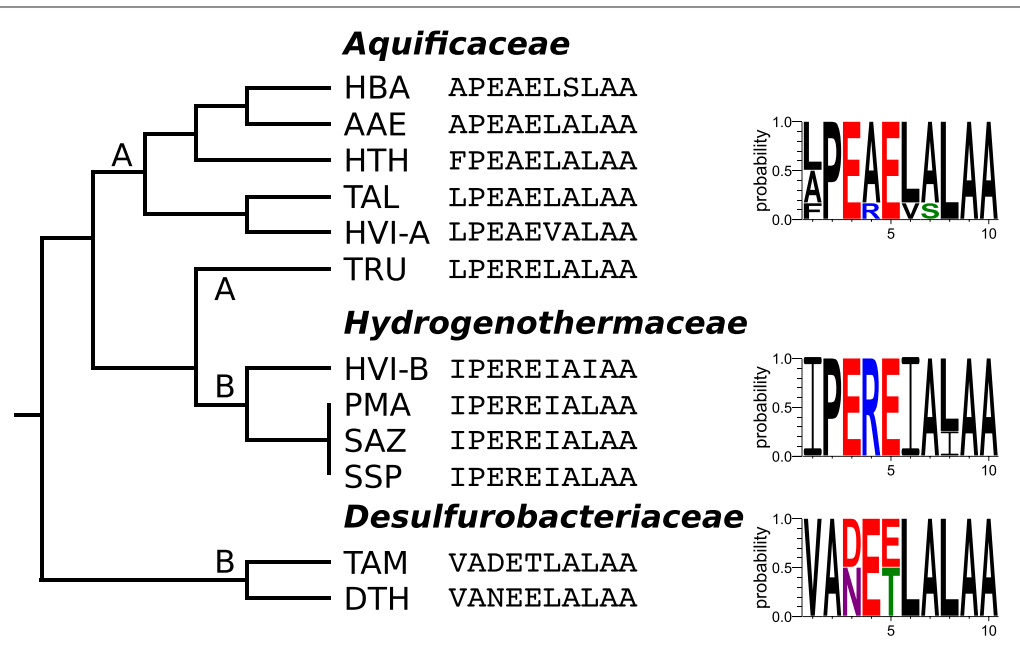

Figure 7 Proteolysis tags of tmRNA types (A/B). The encoded proteolysis tag as well as a probability logo for each family are shown. Two tmRNAs were identified in the genome assembly of Hydrogenivirga sp. 


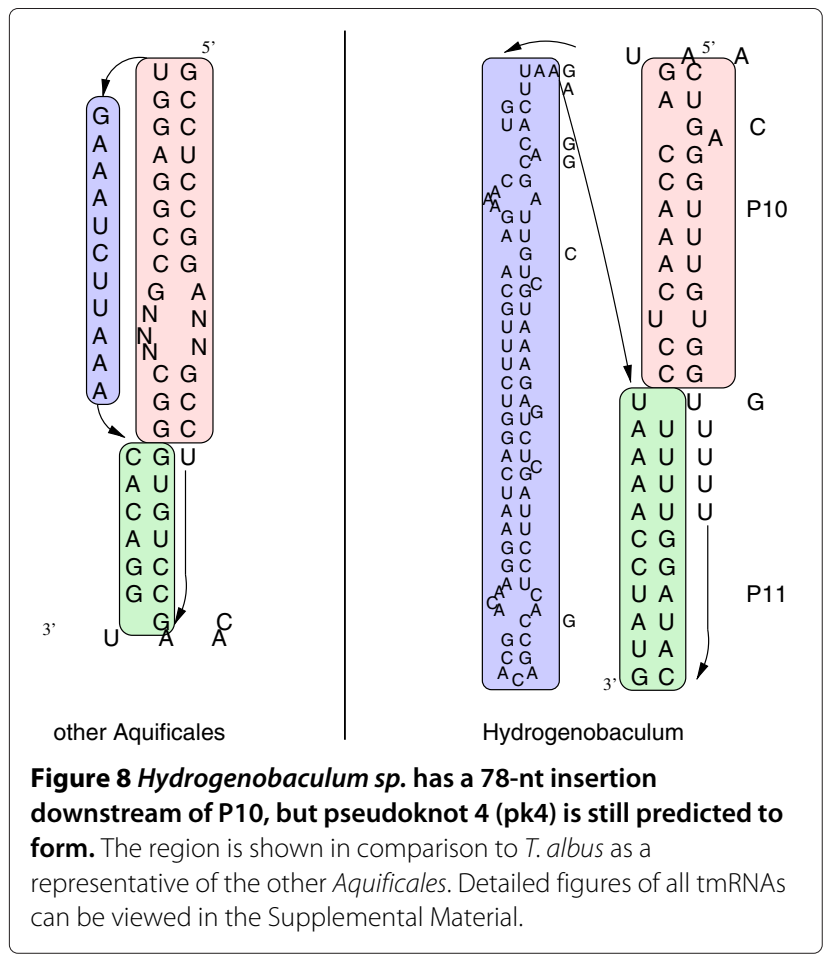

protein cassettes can be seen in Figure 1. In this table we included only CRISPR clusters that were found by both approaches (crt and CRISPRfinder). It has to be kept in mind that the genome of Hydrogenivirga sp. is in an unfinished state, so it is possible that some CRISPR loci and especially associated cas genes escaped detection.

\section{Other nCRNA}

SRP RNA was found once per genome being highly conserved in sequence and structure (see Supplemental Material). Additionally, we show some riboswitch candidates: TPP, MOCO, Cobalamin and $\mathrm{crcB}$ (see Figure 1). The MOCO riboswitch found in T. ammonificans and the two crcB riboswitches identified in Hydrogenobaculum sp. conform well to the Rfam conservation model (see Supplemental Material). Riboswitches were only found sporadically among the Aquificales.

\section{Novel ncRNAs in A. aeolicus}

Besides the annotation of ncRNAs with known functions, we additionally aimed to detect novel ncRNAs, as they often regulate transcription or play an important role as posttranscriptional regulators. Here we combined in silico analysis of the $A$. aeolicus genome and dRNA-seq data from the same organism to identify novel ncRNA candidates, some of which were subsequently analyzed by Northern blot analysis.

In the in silico search, small ncRNAs (sRNAs) were distinguished from proteins by the following analysis steps: (1) The GC-content of the A. aeolicus genome is $43 \%$. However, the ncRNAs described above show an average GC-content of $66 \%$. We associated each nucleotide with a local GC-value. (2) The function of small ncRNAs, e.g. 6S RNA, is often determined by their stable secondary structure. To each position in the genome, we assigned the minimum free energy of the most stable local secondary structure including this nucleotide, using RNALfold. (3) Most ncRNAs are conserved among closely related organisms. We calculated genomewide
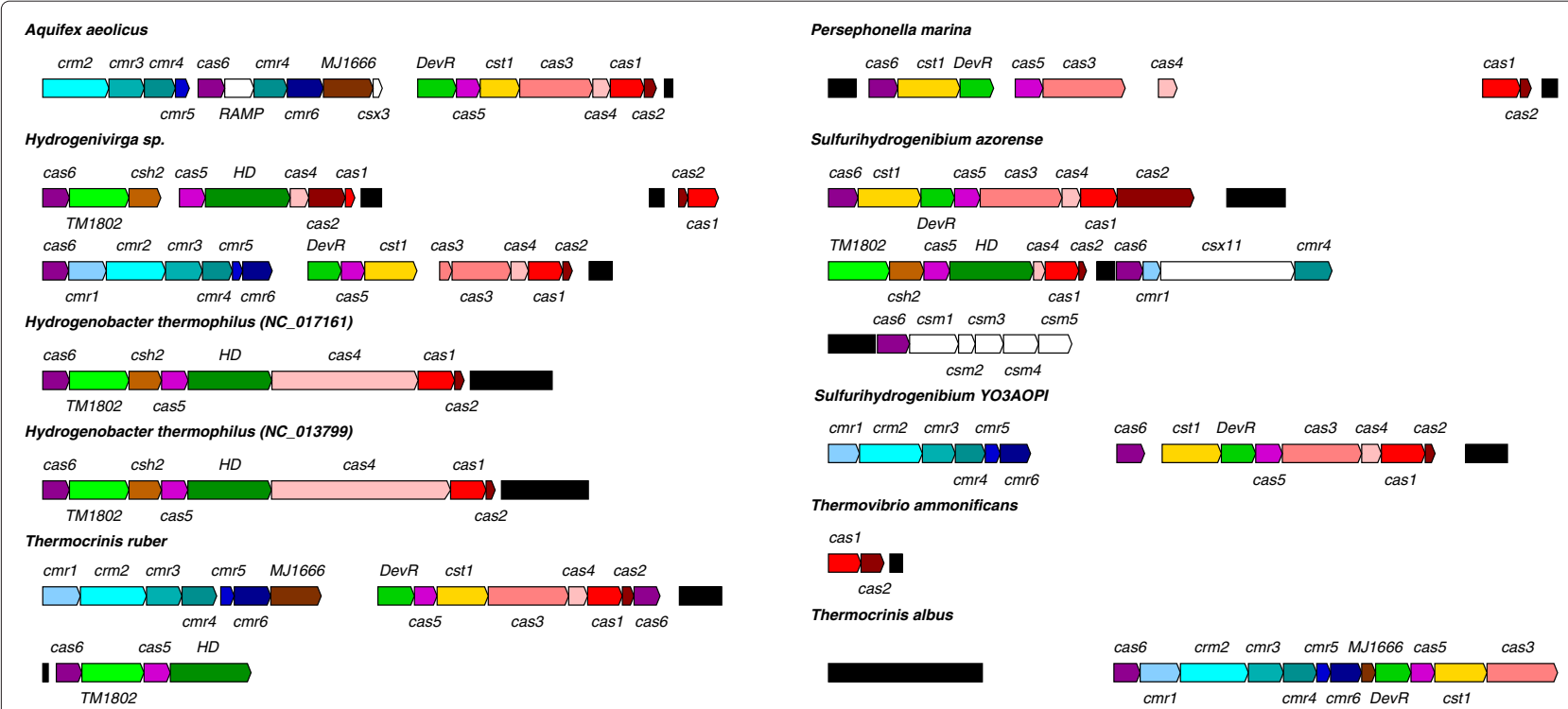

Figure 9 CRISPR clusters and associated cas protein genes in the Aquificales. Shown cas genes and CRISPR clusters (black filled boxes) are proportional in size. As only CRISPR clusters with associated cas genes are displayed in this figure, Hydrogenobaculum sp. and D. thermolithotrophum are not displayed here. 
Table 3 Selection of highly potential novel ncRNA candidates of $A$. aeolicus

\begin{tabular}{|c|c|c|c|c|c|c|c|c|c|c|c|c|}
\hline \multirow[t]{2}{*}{ ID } & \multicolumn{3}{|c|}{ Location } & \multirow[t]{2}{*}{ GC } & \multirow{2}{*}{$\begin{array}{l}\text { CDNA } \\
(+/-)\end{array}$} & \multirow{2}{*}{$\begin{array}{c}\text { Annotation } \\
\text { (NCBI/BacProt) }\end{array}$} & \multicolumn{5}{|c|}{ Structure and Sequence } & \multirow[t]{2}{*}{ Remarks } \\
\hline & 5' boundary & 3' boundary & Strand & & & & RNALfold & Cons_p & Cons_t & RNAz_p & RNAz_t & \\
\hline \multicolumn{13}{|c|}{ Known ncRNAs } \\
\hline 45 & 567675 & 567915 & - & 0.53 & 2237/899 & murF/UDP & -3.89 & 11 & 7 & No & 0.9990 & Downstream of $5 S$ RNA \\
\hline 74 & 1153499 & 1153856 & - & 0.65 & $83 / 31$ & tmRNA/no & -5.04 & 6 & 11 & No & 0.9996 & tmRNA \\
\hline 78 & 1219679 & 1219903 & + & 0.55 & $382 / 1384$ & pheT/pheT & -6.59 & 11 & 11 & No & No & 6S RNA \\
\hline 85 & 1303758 & 1303875 & + & 0.57 & $5239 / 456$ & No/no & -4.15 & 11 & 11 & No & 0.7085 & SRP RNA \\
\hline \multicolumn{13}{|c|}{ Putative Novel ncRNAs } \\
\hline 2 & 15301 & 15474 & + & - & $0 / 0$ & No/no & -3.66 & No & 5 & No & No & Plasmid region \\
\hline 6 & 69101 & 69198 & - & 0.37 & $809 / 545$ & No/no & -4.71 & 11 & 11 & No & No & \\
\hline 25 & 328934 & 328995 & + & 0.37 & $582 / 250$ & No/no & No & 9 & 9 & No & No & \\
\hline 48 & 620054 & 620211 & - & 0.44 & $41 / 71$ & No/no & -3.13 & 11 & 9 & No & No & \\
\hline 58 & 739705 & 739811 & + & 0.44 & $41 / 144$ & No/no & -3.92 & 11 & 11 & No & No & \\
\hline 68 & 989704 & 989840 & + & 0.50 & $476 / 756$ & aq_1392/permease & -4.53 & 4 & 2 & No & No & Aae-65 [85] \\
\hline 74 & 1153547 & 1153769 & + & 0.65 & $326 / 51$ & No/no & -5.04 & 6 & 11 & No & 0.9996 & \\
\hline 75 & 1168974 & 1169071 & - & 0.55 & $158 / 79$ & aq_1666/no & -3.84 & 3 & 3 & No & No & \\
\hline 80 & 1231909 & 1232006 & + & 0.38 & $860 / 2339$ & No/no & -3.74 & 11 & 2 & No & No & \\
\hline 97 & 1491199 & 1491559 & - & 0.40 & 10/297 & rfaG/glycosyltransferase & -4.60 & 11 & 11 & No & No & \\
\hline \multicolumn{13}{|c|}{ Tail to tail Transcripts (T2T) } \\
\hline \multirow[t]{2}{*}{ t2t10 } & 608075 & 608182 & + & 0.52 & $60 / 20$ & aq_880/no & -3.70 & 11 & 11 & No & No & \\
\hline & 608075 & 608308 & - & 0.48 & $22 / 12$ & aq_881/DOXP synthase & -3.70 & 11 & 11 & No & No & \\
\hline \multirow[t]{2}{*}{ t2t17 } & 1336433 & 1336708 & + & 0.46 & $380 / 87$ & aq_1896/predicted & No & 11 & 11 & No & No & \\
\hline & 1336544 & 1336642 & - & 0.51 & $100 / 55$ & folD/folD & No & 11 & 11 & No & No & \\
\hline \multirow[t]{2}{*}{ t2t20 } & 1479248 & 1479345 & + & 0.44 & 180/117 & prmA/prmA & No & 11 & 8 & No & No & \\
\hline & 1479168 & 1479508 & - & 0.43 & $12 / 62$ & acs'/predicted & -3.19 & 11 & 8 & No & No & \\
\hline \multicolumn{13}{|c|}{ tRNAs with sense transcripts only } \\
\hline t06;43 & 383154 & 383390 & - & 0.52 & $9 / 2$ & recN; tRNA/predicted & -3.53 & 11 & 10 & No & 0.9943 & \\
\hline \multicolumn{13}{|c|}{ tRNAs with sense and various antisense transcripts } \\
\hline \multirow[t]{2}{*}{ t34;15 } & 1356464 & 1356743 & + & 0.64 & $23 / 5$ & tRNA/no & -5.43 & 11 & 10 & 0.9996 & 0.9992 & \\
\hline & 1356461 & 1356575 & - & 0.60 & $61 / 15$ & No/no & -5.43 & 11 & 9 & 0.9996 & 0.9992 & \\
\hline \multirow[t]{2}{*}{ t44;20 } & 1531016 & 1531131 & + & 0.58 & $1141 / 437$ & ihfB/no & -4.33 & 7 & 9 & No & 0.9951 & \\
\hline & 1531004 & 1531130 & - & 0.56 & $335 / 136$ & tRNA/no & -4.33 & 7 & 9 & No & 0.9951 & \\
\hline
\end{tabular}

The genomic locations and GC-content are listed in columns 2-4. CDNA - the maximal number of observed read counts in the ( + )- and (-)-library; Annotation - overlap to predicted proteins by NCBI and BacProt; RNALfold - energy in $\mathrm{kcal} / \mathrm{mol}$ of locally stable RNA secondary structure predicted by RNALfold; Cons_p and Cons_t - number of species with homologous regions aligned by Pomago and TBA; RNAz - probabilities $>0.5$ (based on multiple sequence alignments calculated by Pomago (p) or TBA (t)). Further observations, for example that Aae-65 was described earlier in [85], are noted in the last column. A complete list of novel ncRNA candidates, and tRNAs can be found in the Supplemental Material. 
multiple sequence alignments (MSA) with TBA and Pomago of all Aquificales genomes, which can be viewed in the Supplemental Material. (4) Based on the MSAs we performed a novel ncRNA prediction with RNAz and displayed their probability.

All ncRNA candidates with a minimum length of $25 \mathrm{nt}$ and not overlapping protein-coding sequences, rRNA operons or tRNAs, were summarized in a full candidate table, containing all properties mentioned above (see Supplemental Material). A subset of these genes can be seen in Table 3. We identified 99 putative loci for ncRNAs, abbreviated $n 1$ to $n 99$. All above annotated ncRNAs, such as tmRNA (n74) or SRP RNA (n85) were mutually confirmed by our dRNA-seq and in silico approaches. Interestingly, known ncRNAs as well as novel ncRNA candidates show a significant level of antisense transcripts (see examples in Figures 10 and 11). For unknown ncRNAs the sense direction is not assignable. Putative ncRNAs, referring to one genomic location and having comparable numbers of cDNA read counts on both strands, are described with the same ID.

For comparison reasons, we also added tRNAs to our table of ncRNAs, which show the feature of senseantisense (s/as) expression. To exclude the possibility of mapping or other artefacts, we confirmed the presence of antisense transcripts exemplarily by Northern blots for tmRNA and tRNA 44 (Pro-TGG) (Figure 10).

Furthermore, Northern blots were conducted for the loci encoding candidates $\mathrm{n} 25$ and $\mathrm{n} 75$, for which the dRNA-seq data indicated sense and antisense transcription each differing between the (+)- and (-)-library (Figure 11). For n25, we found most transcripts on the plus strand in the (+)-library (582), whereas less than half as many transcripts (250) were detected in the (-)-library. Interestingly, an inverse relation was observed for the minus strand (50/361). For n25, Northern blot detection revealed a signal somewhat shorter than the one expected from the cDNA read boundaries, whereas no signal could be detected for antisense transcripts (Figure 11, top). This finding suggests that the sense transcript is the major one. In the case of $n 75$, both sense and antisense transcripts of comparable intensity were detected, the major signals of the Northern blot representing RNAs larger and smaller than anticipated from the read boundaries (Figure 11, bottom). Thus, the polarity of the putative ncRNA gene remains unclear.

Interestingly, very high transcription levels are found in overlapping 5'-upstream regions of two protein-coding

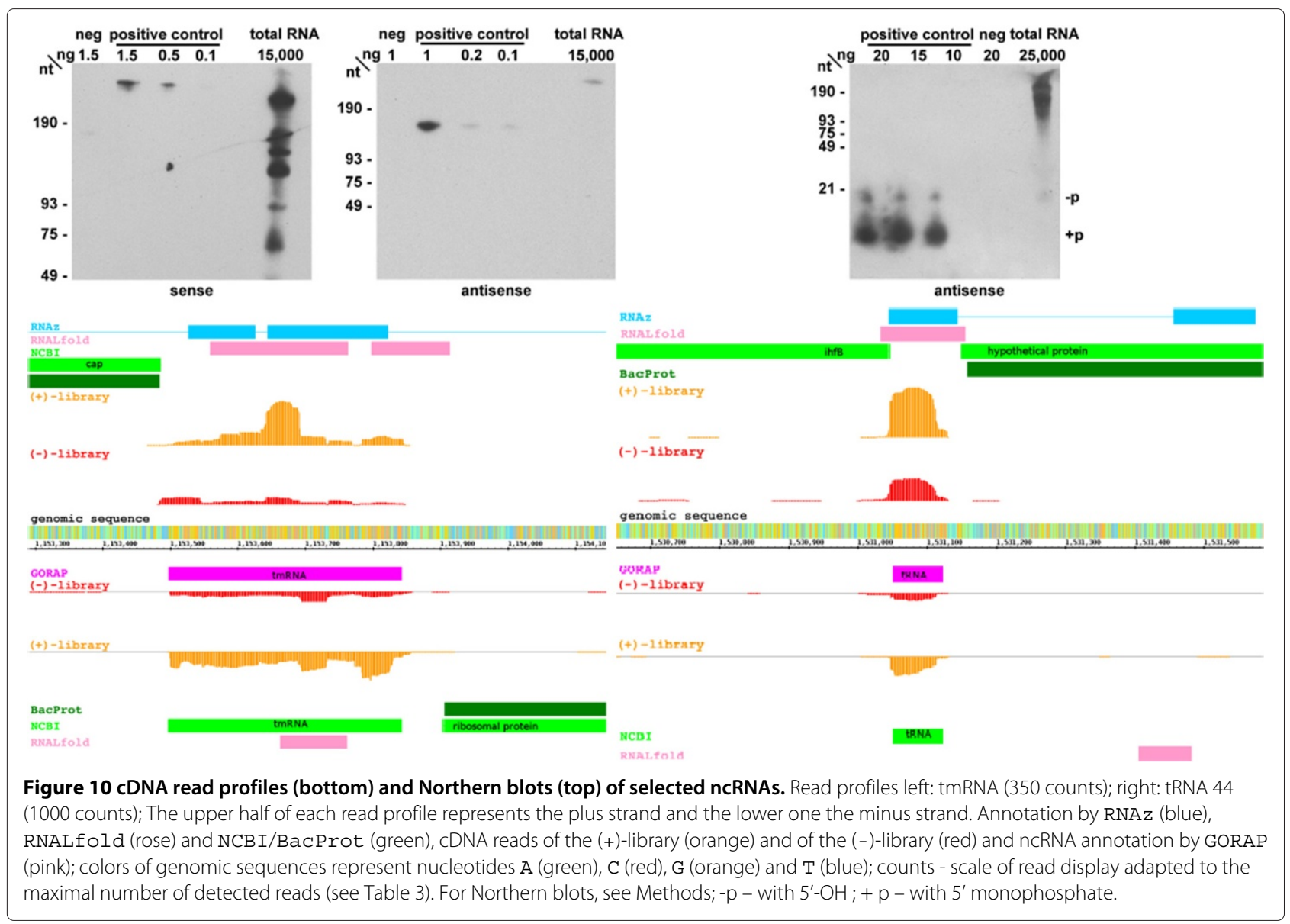




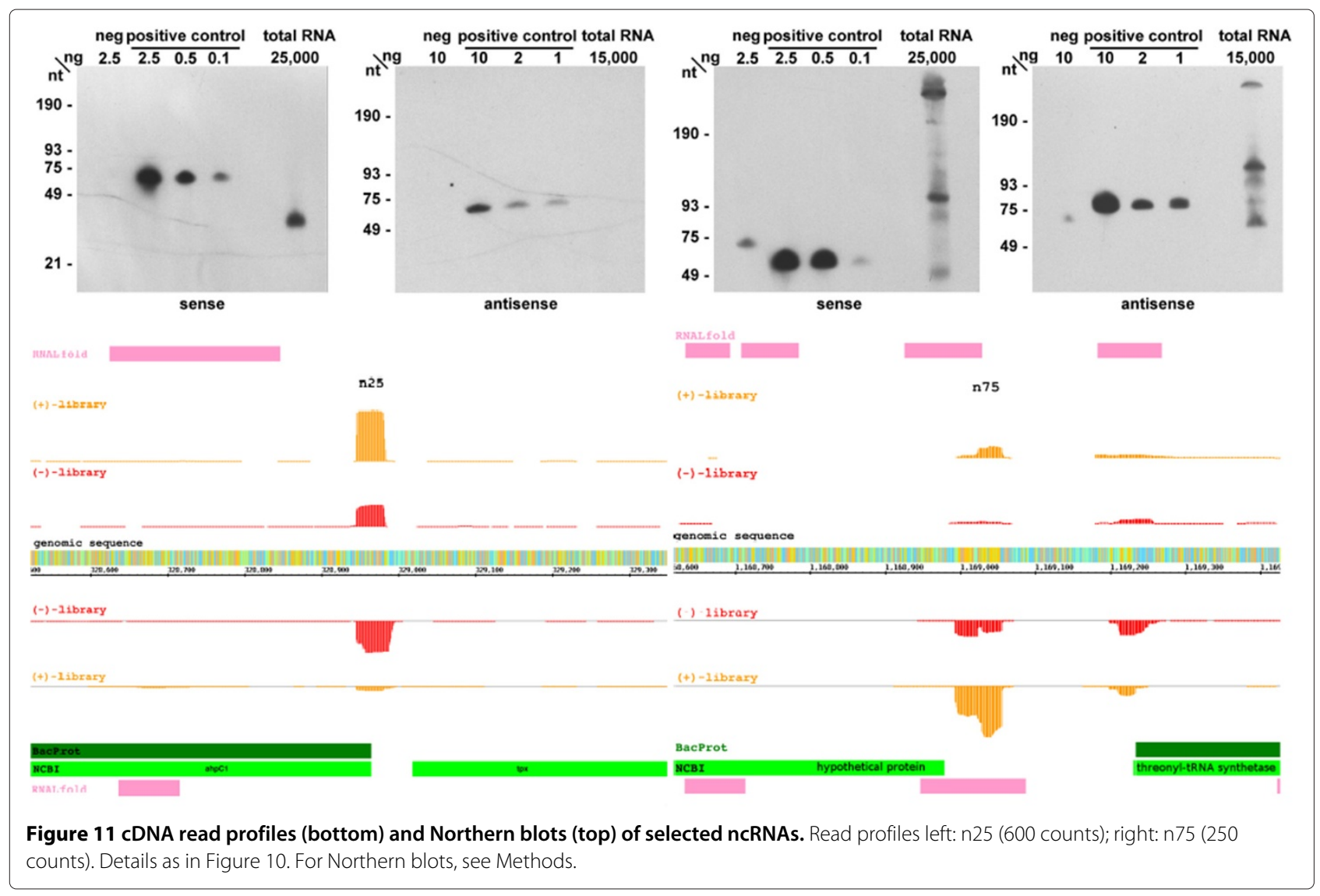

genes located on opposing strands (Table 3). Beside these so-called head-to-head (h2h) transcripts we furthermore observed tail-to-tail overlaps ( $t 2 t$, two 3'-untranslated regions overlapping on opposing strands) that are represented by very high read coverage (Supplemental Material). If these are real transcripts with a certain function or artefacts remains unclear.

\section{Conclusion}

With the advent of a growing number of Aquificales genome sequences in public databases, we have reanalyzed this group of bacteria thriving in extreme environments. The Aquificales share the feature of a small, compact genome with a reduced number of protein and ncRNA genes. The genes for tRNAs are reduced to a minimum but retain the capacity to decode all types of codons, and rRNA genes are confined to 2-3 copies each. Several classical ncRNAs are present, such as SRP RNA, tmRNA, 6S RNA, RNase P RNA (except for all Aquificaceae) and riboswitch candidates in some Aquificales. Furthermore, by combining in silico analysis with dRNA-seq data of $A$. aeolicus, we were able to predict nearly 100 novel ncRNA candidates, some of which might be specific to the Aquificales. Finally, CRISPR systems of bacterial immunity were identified.
Re-annotation of protein genes using BacProt revealed novel proteins with unknown function, some of which might turn out to be specific to the Aquificales as well. On average, 63 additional proteins were found that were missing in the respective original annotation.

In our cDNA libraries of $A$. aeolicus, we observed massive amounts of antisense reads with similar patterns (length and amount) at putative ncRNA loci and terminal regions of mRNAs. Examples of transcripts antisense to tmRNA and tRNA are illustrated in Figure 10.

We compared 40 bacterial and 2 archaeal genomes (see Supplemental Material), and the presence or absence of proteins was used to determine their position in the phylogenetic tree of bacteria. Both Archaea form a clear outgroup. Thermodesulfatator indicus branches first in the group of Bacteria, followed immediately by the Aquificales, while other bacterial branches diverge later. In an additional protein-based analysis, we took the sequences of single-copy orthologs that were present in at least 50\% of all species (concatenated 57,260 aa) (see Supplemental Material). In contrast to the protein presence/absence tree, neither the Aquificales nor T. indicus were placed at a basal position here. However, the two groups are still in close vicinity to each other. This analysis not necessarily excludes the possibility of the Aquificales being a 
basal clade. The selection of orthologs being present in at least $50 \%$ of the species leads to a lower coverage of orthologs present in Archaea species and therefore may favor long branch attraction [99]. The idea behind selecting frequently occurring single-copy orthologs was to produce phylogenetic trees being less influenced by horizontal gene transfer. However, proteins shared by Archaea and Aquificales only are not part of the selected " $50 \%$ group" of proteins and are therefore not considered in this analysis.

Both protein-based phylogenetic trees disagree with a previous study [3] where Desulfobacterium autotrophicum HRM2, a $\delta$-proteobacterium, was added to the Desulfurobacteriaceae family based on $16 \mathrm{~S}$ rRNA analysis. We assume that this was an artefact of the high GC-content of rRNAs due to the high environmental temperatures. Regarding their proteomes, Aquificales and D. autotrophicum are not significantly related.

The results of the $16 \mathrm{~S}$ rRNA phylogenetic analysis did not show a clear picture. Depending on the method used for reconstruction, the Aquificales were either placed near the root of the bacterial tree (MrBayes and RAxML with GTRGAMMA substitution model) or not (NJ and RAxML with GTRCAT) (see Supplemental Material). In accordance with the results of [26], the Aquificales were always placed close to the Thermotogales and Thermales-Deinococcales, Archaea were more closely related to the Aquificales than to the Thermotogales.

We identified two 6S RNA and two tmRNA candidate genes in Hydrogenivirga sp., rather than a single one as in the other Aquificales. Likewise, Hydrogenivirga sp. has a comparatively high amount of tRNA copies and CRISPR loci and its genome is estimated to be of roughly double the size of the other Aquificales genomes. Combined, these observations support the notion that the Hydrogenivirga $s p$. genome assembly is erroneous or two genomes of related bacteria (one type from Hydrogenothermaceae) have entered the sequencing project, being in agreement with [32]. Based on the tmRNA tag peptides identified in the Hydrogenivirga $s p$. assembly, the second one (Hydrogenivirga sp.-B: IPEREIAIAA) matches the sequence exclusively found among the Hydrogenothermaceae, although Hydrogenivirga sp. belongs to the Aquificaceae (see Figure 7). This suggests that the Hydrogenivirga sp. assembly is a blend of sequences from a member of the Aquificaceae and a member of the Hydrogenothermaceae.

\section{Endnote}

${ }^{a}$ Noise cutoff is the highest observed false positive bit score for a potential gene which does not belong to the seed model.

\section{Competing interests}

The authors declare that they have no competing interests.

\section{Authors' contributions}

Bioinformatical analysis: ML, SW, KR, BMB, NW, and MM. Experimental validation: AIN and RKH. Analyzed data: all. Wrote, read and approved the final manuscript: all.

\section{Acknowledgements}

We thank Markus Fricke for tmRNA structure visualization, Brice Felden for tmRNA discussion, J. Sugahara for the SPLITS run in A. aeolicus, Jörg Vogel and Cynthia Sharma from the University of Würzburg for help with differential RNA-Sequencing. MM was funded by the Carl-Zeiss-Stiftung. This work was supported by the DFG-Graduiertenkolleg 1384 "Enzymes and multienzyme complexes acting on nucleic acids" (BMB, ML, MM, RKH, SW), and DFG project MA-5082/1 (MM, SW)

\section{Author details}

${ }^{1}$ Institut für Pharmazeutische Chemie, Philipps-Universität Marburg, Marbacher Weg 6, 35032 Marburg, Germany. ${ }^{2}$ Faculty of Mathematics and Computer Science, Friedrich-Schiller-University Jena, Leutragraben 1, 07743 Jena, Germany. ${ }^{3}$ Faculty of Mathematics and Informatics, University of Leipzig, Augustusplatz 10, 04109 Leipzig, Germany. ${ }^{4}$ IRI for the Life Sciences, Molecular Infection Biology, Humboldt University Berlin, Philippstr. 13, 10115 Berlin, Germany.

Received: 29 November 2013 Accepted: 8 May 2014

Published: 25 June 2014

\section{References}

1. Setchell WA: The upper temperature limits of life. Science 1903, 17(441):934-937.

2. Reysenbach AL, Wickham GS, Pace NR: Phylogenetic analysis of the hyperthermophilic pink filament community in Octopus Spring, Yellowstone National Park. App/ Environ Microbio/ 1994, 60(6):2113-2119.

3. Hügler M, Huber H, Molyneaux SJ, Vetriani C, Sievert SM: Autotrophic $\mathrm{CO} 2$ fixation via the reductive tricarboxylic acid cycle in different lineages within the phylum Aquificae: evidence for two ways of citrate cleavage. Environ Microbiol 2007, 9:81-92.

4. Reysenbach AL: Class I: Aquificae class. nov. Bergey's Manual of Systematic Bacteriology. Edited by Garrity GM, Boone DR, Castenholz RW. New York: Springer-Verlag; 2001:359-367.

5. Bonch-Osmolovskaya E: Aquificales. Chichester: Encyclopedia of Life Sciences (ELS). John Wiley \& Sons, Ltd; 2008.

6. Aravind L, Tatusov RL, Wolf YI, Walker DR, Koonin EV: Evidence for massive gene exchange between archaeal and bacterial hyperthermophiles. Trends Genet 1998, 14(11):442-444.

7. Eder W, Huber R: New isolates and physiological properties of the Aquificales and description of Thermocrinis albus sp. nov. Extremophiles 2002, 6(4):309-318.

8. Santos H, Lamosa P, Borges N, Goncalves L, Pais T, Rodrigues M: Extremophiles Handbook: Organic Compatible Solutes of Prokaryotes that Thrive in Hot Environments: The Importance of lonic Compounds for Thermostabilization: Springer Japan; 2011. [http://dx.doi.org/10.1007/9784-431-53898-1_23]

9. Scholz S, Sonnenbichler J, Schäfer W, Hensel R: Di-myo-inositol-1,1'-phosphate: a new inositol phosphate isolated from Pyrococcus woesei. FEBS Lett 1992, 306(2-3):239-242.

10. Jorge CD, Lamosa P, Santos H: Alpha-D-mannopyranosyl-(1-2)-alphaD-glucopyranosyl-(1-2)-glycer ate in the thermophilic bacterium Petrotoga miotherma-structure, cellular content and function. FEBS $J$ 2007, 274(12):3120-3127.

11. Brosnan CA, Voinnet O: The long and the short of noncoding RNAs. Curr Opin Cell Biol 2009, 21(3):416-425.

12. Collins $L$ : The RNA infrastructure: an introduction to ncRNA networks. Adv Exp Med Biol 2011, 722:1-19.

13. de la Fuente M, Valera S, Martínez-Guitarte JL: ncRNAs and thermoregulation: a view in prokaryotes and eukaryotes. FEBS Lett 2012, 586(23):4061-4069.

14. Marz M, Stadler PF: RNA interactions. Adv Exp Med Bio/ 2011, 722:20-38.

15. Erdmann VA, Barciszewska MZ, Hochberg A, de Groot N, Barciszewski J: Regulatory RNAs. Cell Mol Life Sci 2001, 58(7):960-977. 
16. Barrangou R: CRISPR-Cas systems and RNA-guided interference. Wiley Interdiscip Rev RNA 2013, 4(3):267-278.

17. Macvanin M, Edgar R, Cui F, Trostel A, Zhurkin V, Adhya S: Noncoding RNAs binding to the nucleoid protein $\mathrm{HU}$ in Escherichia coli. J Bacteriol 2012, 194(22):6046-6055.

18. Chevalier C, Boisset S, Romilly C, Masquida B, Fechter P, Geissmann T, Vandenesch F, Romby P: Staphylococcus aureus RNAlll binds to two distant regions of coa mRNA to arrest translation and promote mRNA degradation. PLoS Pathog 2010, 6(3):e1000809.

19. Rice JB, Balasubramanian D, Vanderpool CK: Small RNA binding-site multiplicity involved in translational regulation of a polycistronic mRNA. Proc Natl Acad Sci U S A 2012, 109(40):2691-2698.

20. Pitulle $C$, Yang $Y$, Marchiani M, Moore ER, Siefert JL, Aragno M, Jurtshuk $P$, Fox GE: Phylogenetic position of the genus Hydrogenobacter. Int J Syst Bacteriol 1994, 44(4):620-626.

21. Brown JR, Doolittle WF: Root of the universal tree of life based on ancient aminoacyl-tRNA synthetase gene duplications. Proc Natl Acad SciU S A 1995, 92(7):2441-2445.

22. Bocchetta M, Gribaldo S, Sanangelantoni A, Cammarano P: Phylogenetic depth of the bacterial genera Aquifex and Thermotoga inferred from analysis of ribosomal protein, elongation factor, and RNA polymerase subunit sequences. J Mol Evol 2000, 50(4):366-380.

23. Olsen GJ, Woese CR, Overbeek R: The winds of (evolutionary) change: breathing new life into microbiology. J Bacterio/ 1994, 176:1-6.

24. Baldauf SL, Palmer JD, Doolittle WF: The root of the universal tree and the origin of eukaryotes based on elongation factor phylogeny. Proc Natl Acad Sci U S A 1996, 93(15):7749-7754

25. Wetmur JG, Wong DM, Ortiz B, Tong J, Reichert F, Gelfand DH: Cloning, sequencing, and expression of RecA proteins from three distantly related thermophilic eubacteria. J Bio/ Chem 1994, 269(41):25928-25935

26. Oshima K, Chiba Y, Igarashi Y, Arai H, Ishii M: Phylogenetic position of Aquificales based on the whole genome sequences of six Aquificales species. Int J Evol Biol 2012, 2012:859264-859264.

27. Wieseke N, Lechner M, Ludwig M, Marz M: Pomago: Multiple Genome-Wide Alignment Tool for Bacteria. In Bioinformatics Research and Applications, Volume 7875 of Lecture Notes in Computer Science. Edited by Cai Z, Eulenstein O, Janies D, Schwartz D: Springer Berlin Heidelberg; 2013:249-260. [http://dx.doi.org/10.1007/978-3-642-38036-5_25]

28. Blanchette M, Kent WJ, Riemer C, Elnitski L, Smit AF, Roskin KM, Baertsch R, Rosenbloom K, Clawson H, Green ED, Haussler D, Miller W: Aligning multiple genomic sequences with the threaded blockset aligner. Genome Res 2004, 14(4):708-715.

29. Rose D, Hertel J, Reiche K, Stadler PF, Hackermüller J: NcDNAlign : plausible multiple alignments of non-protein-coding genomic sequences. Genomics 2008, 92:65-74.

30. Nakagawa S, Nakamura S, Inagaki F, Takai K, Shirai N, Sako Y: Hydrogenivirga caldilitoris gen. nov., sp. nov., a novel extremely thermophilic, hydrogen- and sulfur-oxidizing bacterium from a coastal hydrothermal field. Int J Syst Evol Microbiol 2004, 54(Pt 6):2079-2084

31. Nunoura T, Miyazaki M, Suzuki Y, Takai K, Horikoshi K: Hydrogenivirga okinawensis sp. nov., a thermophilic sulfur-oxidizing chemolithoautotroph isolated from a deep-sea hydrothermal field, Southern Okinawa Trough. Int J Syst Evol Microbiol 2008, 58(Pt 3):676-681.

32. Gupta RS, Lali R: Molecular signatures for the phylum Aquificae and its different clades: proposal for division of the phylum Aquificae into the emended order Aquificales, containing the families Aquificaceae and Hydrogenothermaceae, and a new order Desulfurobacteriales ord. nov., containing the family Desulfurobacteriaceae. Antonie Van Leeuwenhoek 2013, 104(3):349-368

33. Lechner M: Detection of Orthologs in large-scale analysis. Master's thesis, University of Leipzig 2009

34. Lechner M, Findeiss S, Steiner L, Marz M, Stadler PF, Prohaska SJ: Proteinortho: detection of (co-)orthologs in large-scale analysis. BMC Bioinformatics 2011, 12:t24.

35. Polard $P$, Prère $M F$, Chandler $M$, Fayet $O$ : Programmed translational frameshifting and initiation at an AUU codon in gene expression of bacterial insertion sequence IS911. J Mol Biol 1991, 222(3):465-477.
36. Spiers AJ, Bergquist PL: Expression and regulation of the RepA protein of the RepFIB replicon from plasmid P307. J Bacteriol 1992, 174(23):7533-7541

37. Binns N, Masters M: Expression of the Escherichia coli pcnB gene is translationally limited using an inefficient start codon: a second chromosomal example of translation initiated at AUU. Mol Microbiol 2002, 44(5):1287-98.

38. Lowe TM, Eddy SR: tRNAscan-SE: a program for improved detection of transfer RNA genes in genomic sequence. Nucl Acids Res 1997, 25:955-964.

39. Sugahara J, Yachie N, Sekine Y, Soma A, Matsui M, Tomita M, Kanai A SPLITS : a new program for predicting split and intron-containing tRNA genes at the genome level. In Silico Biol 2006, 6(5):411-418.

40. Laslett $D$, Canback B: ARAGORN, a program to detect tRNA genes and tmRNA genes in nucleotide sequences. Nucleic Acids Res 2004, 32:11-16

41. Dilimulati Y, Marz M, Stadler PF, Hofacker IL: Bcheck : a wrapper tool for detecting RNase P RNA genes. BMC Genomics 2010, 11:432-440.

42. Bland C, Ramsey TL, Sabree F, Lowe M, Brown K, Kyrpides NC, Hugenholtz $P$ : CRISPR recognition tool (CRT): a tool for automatic detection of clustered regularly interspaced palindromic repeats. $B M C$ Bioinformatics 2007, 8:209-209.

43. Grissa I, Vergnaud G, Pourcel C: CRISPRFinder: a web tool to identify clustered regularly interspaced short palindromic repeats. Nucleic Acids Res 2007, 35(Web Server issue):52-57.

44. Altschul SF, Gish W, Miller W, Myers EW, Lipman DJ: Basic local alignment search tool. J Mol Biol 1990, 215(3):403-410.

45. UniProt Consortium: Reorganizing the protein space at the Universal Protein Resource (UniProt). Nucleic Acids Res 2012, 40(Database issue):71-75.

46. Nawrocki EP, Kolbe DL, Eddy SR: Infernal 1.0 : inference of RNA alignments. Bioinformatics 2009, 25:1335-1337.

47. Gardner PP, Daub J, Tate JG, Nawrocki EP, Kolbe DL, Lindgreen S, Wilkinson AC, Finn RD, Griffiths-Jones S, Eddy SR, Bateman A: Rfam : updates to the RNA families database. Nucleic Acids Res 2009, 37(Database issue):136-140.

48. Wuyts J, Perrière G, Van De Peer Y: The European ribosomal RNA database. Nucleic Acids Res 2004, 32(Database issue):101-103.

49. Eddy SR: RNABOB : a program to search for RNA secondary structure motifs in sequence databases. 1992-1996. [http://selab.janelia.org/ software.html]

50. Hofacker IL, Fekete M, Stadler PF: Secondary structure prediction for aligned RNA sequences. J Mol Bio/ 2002, 319:1059-1066.

51. Hofacker IL: Vienna RNA secondary structure server. Nucleic Acids Res 2003, 31:3429-3431.

52. Hofacker IL, Fontana W, Stadler PF, Bonhoeffer LS, Tacker M, Schuster P: Fast folding and comparison of RNA secondary structures. Monatsh Chem 1994, 125:167-188.

53. Bernhart SH, Hofacker IL, Will S, Gruber AR, Stadler PF: RNAalifold: improved consensus structure prediction for RNA alignments. $B M C$ Bioinformatics 2008, 9:474-474.

54. Thompson JD, Higgins DG, Gibson TJ: CLUSTALW : improving the sensitivity of progressive multiple sequence alignment through sequence weighting, position-specific gap penalties and weight matrix choice. Nucl Acids Res 1994, 22:4673-4680.

55. Otto W, Will S, Backofen R: Structure local multiple alignment of RNA. In Proceedings of German Conference on Bioinformatics (GCB'2008), Volume P-136 of Lecture Notes in Informatics (LNI). Gesellschaft für Informatik (GI): 2008:178-188. [http://dblp.uni-trier.de/db/conf/gcb/gcb2008.html\# OttoWB08]

56. Griffiths-Jones S: RALEE-RNA ALignment editor in Emacs. Bioinformatics 2005, 21:257-259.

57. Federhen S: The NCBI Taxonomy database. Nucleic Acids Res 2012 40(Database issue):D136_D143.

58. Rokas A: Phylogenetic analysis of protein sequence data using the Randomized Axelerated Maximum Likelihood (RAXML) Program. In Current Protocols in Molecular Biology: John Wiley \& Sons, Inc; 2011 Chapter 19 [http://dx.doi.org/10.1002/0471142727.mb1911s96]

59. Subramanian AR, Kaufmann M, Morgenstern B: DIALIGN-TX : greedy and progressive approaches for segment-based multiple sequence alignment. Algorithms Mol Biol 2008, 3:6-6. 
60. Le SQ, Gascuel O: Phylogenetic mixture models for proteins. Mol Biol Evol 2008, 25(7):1307-1320.

61. Katoh K, Misawa K, Kuma K, Miyata T: MAFFT: a novel method for rapid multiple sequence alignment based on fast Fourier transform. Nucleic Acids Res 2002, 30(14):3059-3066

62. Kimura M: A simple method for estimating evolutionary rates of base substitutions through comparative studies of nucleotide sequences. J Mol Evol 1980, 16(2):111-120.

63. Ronquist F, Huelsenbeck JP: MrBayes 3: Bayesian phylogenetic inference under mixed models. Bioinformatics 2003, 19(12):1572-1574.

64. Stamatakis A: RAxML-VI-HPC : maximum likelihood-based phylogenetic analyses with thousands of taxa and mixed models. Bioinformatics 2006, 22(21):2688-2690.

65. Liu K, Raghavan S, Nelesen S, Linder CR, Warnow T: Rapid and accurate large-scale coestimation of sequence alignments and phylogenetic trees. Science 2009, 324(5934):1561-1564.

66. Edgar RC: MUSCLE : a multiple sequence alignment method with reduced time and space complexity. BMC Bioinformatics 2004 5:113-113.

67. Sharma CM, Hoffmann S, Darfeuille F, Reignier J, Findeiss S, Sittka A, Chabas S, Reiche K, Hackermüller J, Reinhardt R, Stadler PF, Vogel J: The primary transcriptome of the major human pathogen Helicobacter pylori. Nature 2010, 464(7286):250-255.

68. Beckmann BM, Burenina OY, Hoch PG, Kubareva EA, Sharma CM, Hartmann RK: In vivo and in vitro analysis of 6S RNA-templated short transcripts in Bacillus subtilis. RNA Bio/ 2011, 8(5):839-849.

69. Huber R, Wilharm T, Huber D, Trincone A, Burggraf S, Konig H, Rachel $R$ Rockinger I, Fricke H, Stetter KO: Aquifex pyrophilus gen.nov., sp.nov., represents a novel group of marine hyperthermophilic hydrogen-oxidizing bacteria. System App/ Microbio/ 1992, 15:340-351.

70. Mattatall NR, Sanderson KE: Salmonella typhimurium LT2 possesses three distinct 23S rRNA intervening sequences. J Bacterio/ 1996, 178(8):2272-2278

71. Nicol JW, Helt GA, Blanchard SG, Raja A, Loraine AE: The Integrated Genome Browser: free software for distribution and exploration of genome-scale datasets. Bioinformatics 2009, 25(20):2730-2731.

72. Deckert G, Warren PV, Gaasterland T, Young WG, Lenox AL, Graham DE, Overbeek R, Snead MA, Keller M, Aujay M, Huber R, Feldman RA, Short JM, Olsen GJ, Swanson RV: The complete genome of the hyperthermophilic bacterium Aquifex aeolicus. Nature 1998 392(6674):353-358

73. Hoffmann S, Otto C, Kurtz S, Sharma CM, Khaitovich P, Vogel J, Stadler PF, Hackermüller J: Fast mapping of short sequences with mismatches, insertions and deletions using index structures. PLoS Comput Biol 2009, 5(9):e1000502.

74. Beckmann BM, Grünweller A, Weber MH, Hartmann RK: Northern blot detection of endogenous small RNAs (approximately $14 \mathrm{nt}$ ) in bacterial total RNA extracts. Nucleic Acids Res 2010, 38(14):e147.

75. NCBI: Genome information by organism. [http://www.ncbi.nlm.nih gov/genomes/lproks.cgi] (accessed 2013-08-05).

76. Reysenbach AL, Hamamura N, Podar M, Griffiths E, Ferreira S, Hochstein R, Heidelberg J, Johnson J, Mead D, Pohorille A, Sarmiento M, Schweighofer $\mathrm{K}$, Seshadri R, Voytek MA: Complete and draft genome sequences of six members of the Aquificales. J Bacteriol 2009, 191(6):1992-1993.

77. Washietl S, Hofacker IL, Stadler PF: Fast and reliable prediction of noncoding RNAs. Proc Natl Acad Sci U S A 2005, 102:2454-2459.

78. Kuratani M, Ishii R, Bessho Y, Fukunaga R, Sengoku T, Shirouzu M, Sekine S, Yokoyama S: Crystal structure of tRNA adenosine deaminase (TadA) from Aquifex aeolicus. J Biol Chem 2005, 280(16):16002-16008.

79. Kuratani M, Yoshikawa Y, Bessho Y, Higashijima K, Ishii T, Shibata R, Takahashi S, Yutani K, Yokoyama S: Structural basis of the initial binding of tRNA(Ile) lysidine synthetase TilS with ATP and L-lysine. Structure 2007, 15(12):1642-1653.

80. Soma A, Ikeuchi Y, Kanemasa S, Kobayashi K, Ogasawara N, Ote T, Kato J, Watanabe K, Sekine $Y$, Suzuki T: An RNA-modifying enzyme that governs both the codon and amino acid specificities of isoleucine tRNA. Mol Cell 2003, 12(3):689-698.

81. Muramatsu T, Nishikawa K, Nemoto F, Kuchino Y, Nishimura S, Miyazawa T, Yokoyama S: Codon and amino-acid specificities of a transfer RNA are both converted by a single post-transcriptional modification. Nature 1988, 336(6195):179-181.
82. Muramatsu T, Yokoyama S, Horie N, Matsuda A, Ueda T, Yamaizumi Z, Kuchino Y, Nishimura S, Miyazawa T: A novel lysine-substituted nucleoside in the first position of the anticodon of minor isoleucine tRNA from Escherichia coli. J Bio/ Chem 1988, 263(19):9261-9267.

83. Voorhees RM, Mandal D, Neubauer C, Köhrer C, RajBhandary UL, Ramakrishnan $\mathrm{V}$ : The structural basis for specific decoding of AUA by isoleucine tRNA on the ribosome. Nat Struct Mol Biol 2013 20(5):641-643.

84. Marszalkowski M, Teune JH, Steger G, Hartmann RK, Willkomm DK: Thermostable RNase P RNAs lacking P18 identified in the Aquificales. RNA 2006, 12(11):1915-1921.

85. Willkomm DK, Minnerup J, Hüttenhofer A, Hartmann RK: Experimental RNomics in Aquifex aeolicus: identification of small non-coding RNAs and the putative 6S RNA homolog. Nucleic Acids Res 2005 33(6):1949-1960.

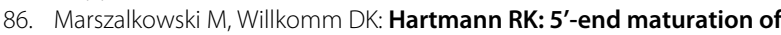
tRNA in Aquifex aeolicus. Biol Chem 2008, 389(4):395-403.

87. Marszalkowski M, Willkomm DK, Hartmann RK: Structural basis of a ribozyme's thermostability: P1-L9 interdomain interaction in RNase P RNA. RNA 2008, 14:127-133.

88. Trotochaud AE, Wassarman KM: A highly conserved 6S RNA structure is required for regulation of transcription. Nat Struct Mol Biol 2005, 12(4):313-319.

89. Barrick JE, Sudarsan N, Weinberg Z, Ruzzo WL: Breaker RR: 6S RNA is a widespread regulator of eubacterial RNA polymerase that resembles an open promoter. RNA 2005, 11(5):774-784.

90. Beckmann BM, Hoch PG, Marz M, Willkomm DK, Salas M, Hartmann RK: A pRNA-induced structural rearrangement triggers 6S-1 RNA release from RNA polymerase in Bacillus subtilis. EMBO J 2012, 31(7):1727-1738.

91. Wassarman KM, Saecker RM: Synthesis-mediated release of a small RNA inhibitor of RNA polymerase. Science 2006, 314(5805):1601-1603.

92. Neusser T, Gildehaus N, Wurm R, Wagner R: Studies on the expression of 6S RNA from $E$. coli: involvement of regulators important for stress and growth adaptation. Biol Chem 2008, 389(3):285-297.

93. Gildehaus N, Neusser T, Wurm R, Wagner R: Studies on the function of the riboregulator $6 \mathrm{~S}$ RNA from $E$. coli: RNA polymerase binding, inhibition of in vitro transcription and synthesis of RNA-directed de novo transcripts. Nucleic Acids Res 2007, 35(6):1885-1896.

94. Karzai AW, Roche ED, Sauer RT: The SsrA-SmpB system for protein tagging, directed degradation and ribosome rescue. Nat Struct Biol 2000, 7(6):449-455.

95. Tanner DR, Dewey JD, Miller MR, Buskirk AR: Genetic analysis of the structure and function of transfer messenger RNA pseudoknot 1. J Biol Chem 2006, 281(15):10561-10566.

96. Zwieb C, Gorodkin J, Knudsen B, Burks J, Wower J: tmRDB (tmRNA database). Nucleic Acids Res 2003, 31:446-447.

97. Horvath P, Barrangou R: CRISPR/Cas, the immune system of bacteria and archaea. Science 2010, 327(5962):167-170.

98. Maaty WS, Ortmann AC, Dlakič M, Schulstad K, Hilmer JK, Liepold L, Weidenheft B, Khayat R, Douglas T, Young MJ, Bothner B: Characterization of the archaeal thermophile Sulfolobus turreted icosahedral virus validates an evolutionary link among double-stranded DNA viruses from all domains of life. J Virol 2006 80(15):7625-7635.

99. Li YW, Yu L, Zhang YP: Long-branch attraction artifact in phylogenetic reconstruction. Yi Chuan 2007, 29(6):659-667.

doi:10.1186/1471-2164-15-522

Cite this article as: Lechner et al.: Genomewide comparison and novel ncRNAs of Aquificales. BMC Genomics 2014 15:522. 